\title{
Plant Life Cycle and Aggregate Employment Dynamics*
}

\author{
Min Ouyang ${ }^{\dagger}$ \\ University of California at Irvine
}

June 2006

\begin{abstract}
Past empirical studies have repeatedly found the link between plant life cycle and aggregate employment dynamics: cross-section aggregate employment dynamics differ significantly by plant age. Interestingly, the dynamics of plant-level productivity distribution also display a strong age pattern. This paper develops a model of plant life cycle with demand fluctuations, to capture both of these empirical regularities. We model plants to differ by vintage, and an idiosyncratic component that is not directly observable, but can be learned over time. We show that this model, developed to match the observed dynamics of plant-level productivity distribution, introduces two driving forces for job flows: learning and creative destruction. The resulting job flows can match, both qualitatively and quantitatively, the differences between young and old plants in their job-flow magnitude and cyclical responses observed in the U.S. manufacturing sector.

Keywords: Plant life cycle; Employment dynamics; Heterogeneous Employers; Job creation; Job destruction; Productivity dynamics; Demand fluctuations.
\end{abstract}

JEL: E32, L16, C61

${ }^{*}$ I am indebt to John Haltiwanger, Michael Pries, John Rust, John Shea and Deniel Vincent at University of Maryland for their support and encouragement, as well as to Bill Branch, Jan Brueckner, Michelle Garfinkel, Igor Kopylov, and Michael McBride at University of California - Irvine for their comments. Other seminar participants at UMD, UCSD, and UCI also provided very helpful suggestions for this paper.

${ }^{\dagger}$ Department of Economics, University of California at Irvine. Address: 3151 Social Science Plaza B, Irvine, CA, 92697. Email: mouyang@uci.edu. 


\section{Introduction}

In recent years, with longitudinal business data bases becoming more available, our understanding of the micro foundations of aggregate employment dynamics has much improved. We now know that, in the real world, the traditional representative-employer paradigm does not hold. As a matter of fact, economies across time and regions are characterized by large and pervasive job flows due to entry, exit, expansion and contraction of businesses. Davis and Haltiwanger (1999) document that this is true even when looking at very narrowly defined industries. Their finding has stimulated an interest in theoretical models that emphasize reallocation across heterogeneous employers. ${ }^{1}$

Two empirical regularities have been pointed out for such models to explain. First, job reallocation exceeds that necessary to implement observed net job growth. ${ }^{2}$ This implies that jobs are continually being reallocated across businesses within the same industry. Hence, the observed job flows should not reveal employment movements across industries. Rather, they reflect businesses' idiosyncratic characteristics and resulting heterogeneous labor demand. Second, job-flow patterns differ significantly by plant age in both magnitudes and cyclical responses, suggesting a link between plant life cycle and aggregate employment dynamics. ${ }^{3}$ According to Davis and Haltiwanger (1999), this link is strong and persistent: it exists in very narrowly defined (four-digit) manufacturing industries even within specific geographic regions. If the existence of large-scale job flows within narrowly defined industries reflects the importance of heterogeneous labor demand at the plant level, then the strong age pattern of job flows suggests that plant-level labor demand changes significantly over plants' life cycle. This paper proposes a theory motivated by those findings.

What can be the driving force for the age differences of plant-level labor demand? Campbell and Fisher (2004) argue that it can be the adjustment cost proportional to the number of jobs created or destroyed. They show that a model with such adjustment costs, together with the opportunity to substitute between structured and unstructured jobs, can match much of the observed job-flow differences at young and old plants. In this paper, we take a different approach. We propose that it can be the dynamics of plant-level productivity that drives the dynamics of plant-level labor demand. We build a model to highlight the following relative advantages and disadvantages of young and old plants. Intuitively, old plants tend to be more productive since they have already survived a long time; but they may be using out-dated technologies or producing products flagging in popularity. Young plants, by contrast, are more likely to be technologically advanced although they have not survived long. If these conjectures are true and if, in addition, more productive plants hire more labor, then there are multiple margins for a plant to create or destroy jobs as it ages. And the interactions of these margins with the business cycles give rise to the cyclical aggregate

\footnotetext{
${ }^{1}$ See Hall (1992, 2000), Mortensen and Pissarides (1994), Caballero and Hammour (1994, 1996), Campbell and Fisher (1998, 2004), Barlevy (2002), Gomes, Greenwood, and Rebelo (2001), Ouyang (2005).

${ }^{2}$ Davis and Haltiwanger (1999) document that, employment shifts among the approximately 450 four-digit industries in the U.S. manufacturing sector account for a mere $13 \%$ of excess job reallocation. Simultaneously cutting the U.S. manufacturing data by state and two-digit industry, region, size class, age class and ownership type, betweensector shifts account for only 39 percent of excess job reallocation. The same finding holds up in studies for other countries(e.g. Nocke 1994).

${ }^{3}$ See Dunne, Roberts and Samuelson (1989), Evans (1987), Troske (1996), Davis and Haltiwanger (1999).
} 
employment dynamics.

What does the evidence on plant-level productivity say? Most interestingly, it says that the distribution of plant-level productivity also displays a strong age pattern. In the U.S. manufacturing industries, entering plants are more productive than incumbents on average; and, as a birth cohort of plants grow older, their average productivity increases but the productivity dispersion declines. ${ }^{4}$ This age pattern has been found within very narrowly defined industries, just like that of jobreallocation rates. The coexistence of the age pattern of job flows and the age pattern of productivity distribution gives rise to a natural question whether they can be reconciled.

This paper brings this evidence together by showing that a model reflecting the documented productivity dynamics will generate job flows that feature the observed patterns in the U.S. manufacturing sector. ${ }^{5}$ The model allows plants to differ in terms of vintage and unobservable idiosyncratic productivity. The vintage component makes entering plants more productive than incumbents on average. The idiosyncratic productivity is not directly observable, but can be learned over time. As a birth cohort grows older, more and more of its plants with low idiosyncratic productivity exit, bringing up the within-cohort average productivity but driving down the within-cohort productivity dispersion, just as the data shows.

With those productivity dynamics, multiple job reallocation margins arise. Some job flows are driven by a learning force. A plant increases its employment (creates jobs) when it learns its true idiosyncratic productivity is high; it exits (destroys jobs) when learning that its idiosyncratic productivity is low. Meanwhile, as new plants continually enter with more advanced technology, incumbents becomes more and more technologically outdated. They tend to destroy jobs and eventually leave the market at a certain age. This generates a creative destruction force that drives job creation at technologically more advanced entering plants and job destruction at outdated ones.

The resulting employment dynamics matches the observed magnitude of job flows over the plant life cycle. Because learning diminishes with age, job creation and destruction decline with plant age; while large job flows still exist among mature plants with outdated plants being replaced due to creative destruction. The model also matches the observed cyclical pattern of job flows with plant age. The learning force generates more symmetric cyclical responses on the creation and destruction sides, while the creative destruction force makes job destruction more responsive. Since learning diminishes with plant age, the impact of learning dominates for young plants and that of creative destruction dominates for old plants. Therefore, in our model, the variance ratio of job destruction over job creation increases with plant age, as shown in the data.

In developing such a model, we reconcile the observed age dynamics of plant productivity distribution and the age dynamics of employment reallocation. The relationship between the two has been recognized in the literature. As we have argued, large-scale job flows and enormous heterogeneity in plant-level productivity co-exist within narrowly defined industries, implying that plant-level

\footnotetext{
${ }^{4}$ See Baily, Hulten and Campbell (1992), Bahk and Gort (1993), Aw, Chen and Roberts (1997), Jensen, McGuckin and Stiroh (2000), Foster, Haltiwanger and Syverson (2005).

${ }^{5}$ Similar patterns have also been found in data on job flows in France, Canada, Norway, Neterlands, Germany and U.K.. See Davis and Haltiwanger (1999).
} 


\begin{tabular}{|c|c|c|c|c|c|c|}
\hline \multicolumn{7}{|c|}{ A. Means } \\
\hline Plant type & $E(C b)$ & $E(C c)$ & $\mathbf{E}(\mathbf{C})$ & $E(D d)$ & $E(D c)$ & $\mathbf{E}(\mathbf{D})$ \\
\hline all & 0.42 & 4.77 & 5.20 & 0.64 & 4.89 & 5.53 \\
\hline young & 1.52 & 6.00 & 7.52 & 1.24 & 5.33 & 6.56 \\
\hline old & 0.12 & 4.42 & 4.54 & 0.47 & 4.77 & 5.24 \\
\hline \multicolumn{7}{|c|}{ B. Variance ratio of job destruction to creation } \\
\hline plant type & \multicolumn{3}{|c|}{$\boldsymbol{\sigma}(\mathbf{D})^{2} / \boldsymbol{\sigma}(\mathbf{C})^{2}$} & \multicolumn{3}{|c|}{$\sigma(D c)^{2} / \sigma(C c)^{2}$} \\
\hline all & \multicolumn{3}{|c|}{3.49} & \multicolumn{3}{|c|}{3.64} \\
\hline young & \multicolumn{3}{|c|}{1.32} & \multicolumn{3}{|c|}{2.80} \\
\hline old & \multicolumn{3}{|c|}{4.18} & \multicolumn{3}{|c|}{3.69} \\
\hline
\end{tabular}

Table 1: Quarterly gross job flows from plant birth, plant death, and continuing operating plants in the US manufacturing sector: 1973 II to 1988 IV. Young plants are defined as those younger than 40 quarters. Cb denotes job creation from plant birth, Dd job destruction from plant death, $\mathrm{Cc}$ and Dc job creation and destruction from continuing operating plants.ong old plants, although old plants are those older than 40 quarters. C and D represent gross job creation and destruction. $\mathrm{C}=\mathrm{Cc}+\mathrm{Cb}, \mathrm{D}=\mathrm{Dd}+\mathrm{Dc}$. All numbers are in percentage points.

productivity can dominate the determination of which plants create or destroy jobs. Furthermore, several empirical studies have found that the reallocation of inputs from less-productive to more-productive plants plays a major role in industry-level productivity dynamics. ${ }^{6}$ These studies provide direct evidence that favors our view that productivity dynamics and employment dynamics should be reconciled.

This paper makes two contributions. First, it contributes to the job-flow literature by providing an explanation for the observed age pattern, in addition to that in Campbell and Fisher (2004). It also contributes to the literature exploring the micro foundations of aggregate dynamics, which has grown in recent years as the traditional representative-employer paradigm challenged by various evidence such as large-scale job flows and productivity variation. An assortment of research has arisen exploring growth and business cycles with heterogeneous-employer models. The theoretical framework developed in this paper provides a starting point for future research that looks more intensively into this direction.

We proceed as follows. In the next section, we describe the differences in young and old plants' job-flow magnitudes and cyclical responses that motivate our theory. Section 3 presents the model, with which we analyze the job-flow patterns over a plant's life cycle in Section 4. A calibrated version of the model is studied numerically in Section 5. We conclude in section 6 .

\section{Plant Age and Gross Job Flows}

This section describes the evidence on the age patterns of gross job flows. We separate gross job flows into two components: the number of jobs created at expanding and newly born plants

\footnotetext{
${ }^{6}$ See Baily, Hulten, and Campbell (1992), Olley and Pakes (1996), Bartelsman and Dhrymes (1994), Bailey, Bartelsman and Haltiwanger (2001), and Foster, Haltiwanger and Krizan (2002).
} 

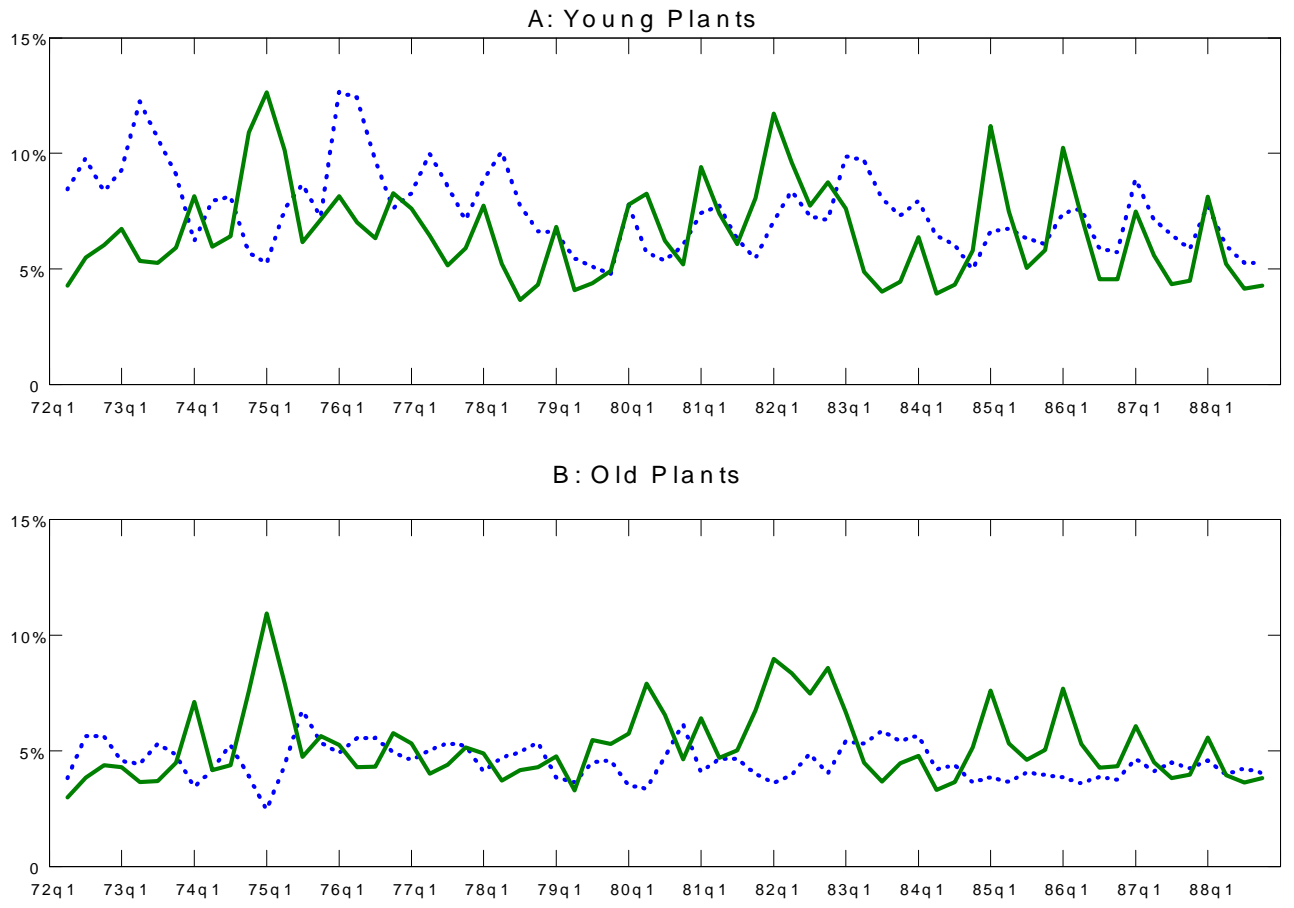

Figure 1: Job flows at young and old plants, 1972:2 - 1988:4. Dashed lines represent the job creation series; solid lines represent job destruction. 
(job creation) and the number of jobs lost at declining and closing plants (job destruction). The magnitudes and cyclical responses of job creation and destruction differ significantly by plant age. More specifically, both job creation and destruction rates are larger in magnitude for younger plants. At the same time, job destruction varies more over time than job creation at older plants, while the variation of job creation and that of job destruction at younger plants are much more symmetric.

These patterns are displayed in Table 1 and Figure 1. Our data source is Davis, Haltiwanger and Shuh's observations of job creation and destruction rates for the US manufacturing sector. The sample covers the statistics from the second quarter of 1972 to the fourth quarter of 1988 . We use their quarterly job creation and destruction series for plants in three different age categories. Davis, Haltiwanger and Schuh (1996, p.225) recommend aggregating the two categories that include the youngest plants, and we do this here. They also document that these patterns are also evident with more detailed age categories.

In Table 1A, young plants' average job creation rate and destruction rate are both higher than those of old plants. In Table 1B, the variance ratio of job destruction and creation is 4.18 for old plants, suggesting a more volatile job destruction; but it is only 1.32 for young plants, implying approximately equally volatile job destruction and creation. As Table 1 shows, the age differences in magnitude and the relative volatility of destruction and creation persist even after separating job-flow rates into those by plant birth, plant death, and continuing operating plants. ${ }^{7}$ The related time series are presented in Figure 1, reinforcing those impressions.

The sharp relationship between plant age and gross job flows, as revealed in Table 1 and Figure 1 , suggests the link between plant life cycle and aggregate employment dynamics. This link has been theoretically explored in Campbell and Fisher (2004), who models the adjustment costs that are proportional to the number of jobs created or destroyed. In their environment, a plant currently adjusting employment is more likely to do so again in the immediate future. Since by definition entrants must adjustment employment, the frequency of employment adjustment naturally declines with plant age. Their model well matches the larger job flow rates and heightened employment volatility at young plants, but leaves much of the relative volatility of job destruction and creation unexplained. As stated in Campbell and Fisher (2002), their model "counterfactually predicts that the variance ratios are either close to or less then one" (page 349). ${ }^{8}$ However, Table 1 documents that the variance ratio of job destruction and creation is 4.18 for old manufacturing plants, and 3.49 for the total manufacturing sector, both significantly greater than one. This highlights the need for a more complete explanation for young and old plants' different dynamic behavior.

The model presented in the next section takes a different approach. Our focus is the heterogeneity in plant productivity. We develop a model in which plant-level productivity are decomposed

\footnotetext{
${ }^{7}$ Notice that in Table 1, job creation from plant birth is not zero among old plants, although old plants are those older than 40 quarters. This comes from the definition of plant age and plant birth. Plant age is calculated from the first time a plant is observed with positive employment. Plant birth is recorded when a plant's employment level going from zero to above zero. Some old plants' employment may temporarily drop to zero and rise again, which generates job creation from plant birth at old plants.

${ }^{8}$ Campbell and Fisher (2000) show a model with real wage shocks that can raise the variance ratio greater than one.
} 
to match the cross-section productivity variation as well as dynamics of productivity distribution observed in the U.S. manufacturing sector. Our purpose is to show that such a model developed according to observed productivity dynamics, can also generate aggregate employment dynamics at young and old plants as illustrated in Table 1 and Figure 1.

\section{A Model of Learning and Creative Destruction}

Consider an industry of plants that combine labor and capital in fixed proportions to produce a single good. Plants hire labor in a competitive labor market. Each plant consists of:

1. machines embodying a technology of some vintage;

2. a group of employees; and

3. an unobservable idiosyncratic productivity component.

There is an exogenous technological progress that drives the most advanced technology, denoted by $A$, growing over time at rate, $\gamma>0$. When entering the market, a plant adopts the most advanced technology at the time, which remains constant afterward and becomes this plant's vintage. Let $A(a)$ represent the vintage of a plant of age $a$, or, in another word, the most advanced technology $a$ periods ago.

$$
A(a)=A \cdot(1+\gamma)^{-a}
$$

When entering the market, a plant is also endowed with idiosyncratic productivity, denoted by $\theta$. It can represent the talent of the manager as in Lucas (1978), or alternatively, the location of the store, the organizational structure of the production process, or its fitness to the embodied technology. The key assumption regarding $\theta$ is that its value, although fixed at the time of entry, is not directly observable.

Production takes place through a group of workers. $n$ represents the plant's employment level. The output of this plant is given by

$$
A(a) \cdot x \cdot n^{\alpha}, \quad 0<\alpha<1
$$

where

$$
x=\theta+\varepsilon .
$$

The shock $\varepsilon$ is an i.i.d. random draw from a fixed distribution that masks the influence of $\theta$ on output. Output is directly observable. Since the plant knows its vintage, it can infer the value of $x$. The plant uses its observations of $x$ to learn about $\theta$.

\section{1 "All-Or-Nothing" Learning}

Plants are price takers and profit maximizers. While deciding whether to continue or terminate production and to choose the optimal level of employment, plants attempt to resolve the uncertainty 


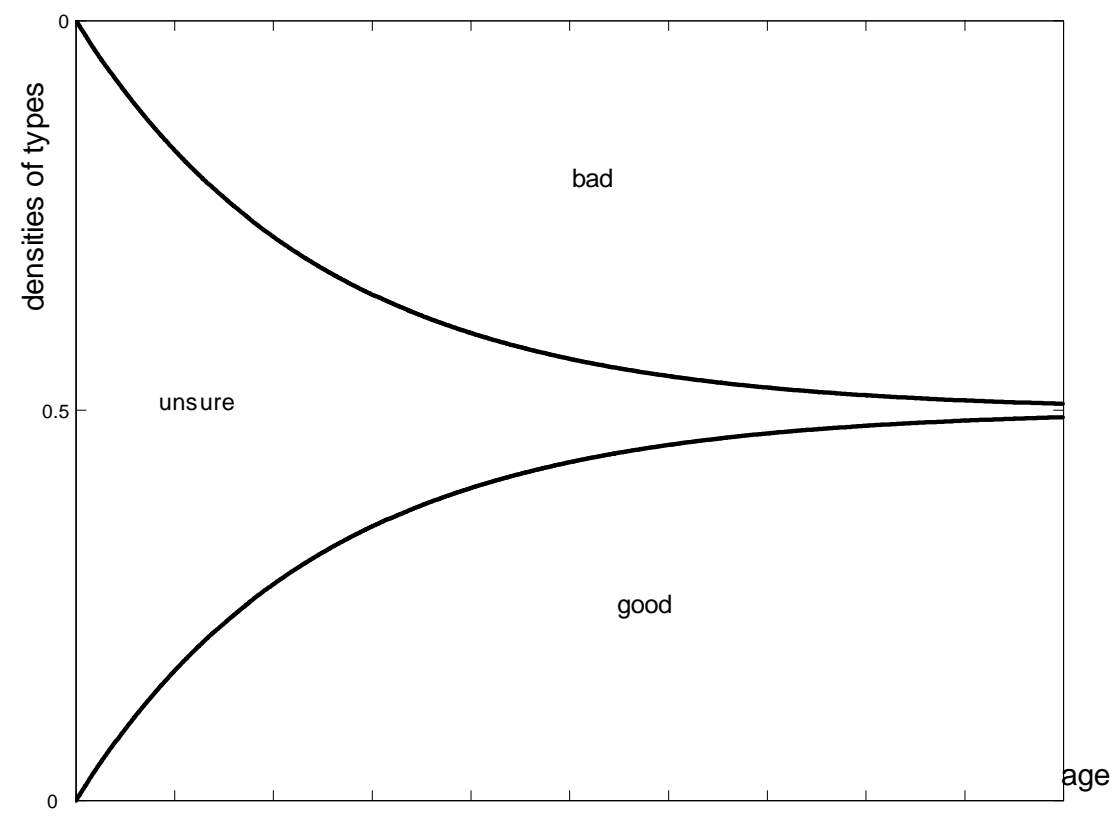

Figure 2: Dynamics of a Birth Cohort with Learning: the distance between the concave curve and the bottom axis measures the density of plants with $\theta^{e}=\theta_{g}$; the distance between the convex curve and the top axis measures the density of plants with $\theta^{e}=\theta_{b}$; and the distance between the two curves measures the density of unsure plants (plants with $\theta^{e}=\theta_{u}$ ).

about $\theta$. The random component $\varepsilon$ represents transitory factors that are independent of the idiosyncratic productivity $\theta$. By assuming that $\varepsilon$ has mean zero, we have $E(x)=E(\theta)+E(\varepsilon)=E(\theta)$.

Given knowledge of the distribution of $\varepsilon$, a sequence of observations of $x$ allows the plant to learn about its $\theta$. Although a continuum of potential values for $\theta$ is more realistic, for simplicity it is assumed here that there are only two values: $\theta_{g}$ for a good plant and $\theta_{b}$ for a bad plant. Furthermore, $\varepsilon$ is assumed to be distributed uniformly on $[-\omega, \omega]$. Therefore, a good plant will have $x$ each period as a random draw from a uniform distribution over $\left[\theta_{g}-\omega, \theta_{g}+\omega\right]$, while the $x$ of a bad plant is drawn from an uniform distribution over $\left[\theta_{b}-\omega, \theta_{b}+w\right]$. Finally, $\theta_{g}, \theta_{b}$ and $\omega$ satisfy $0<\theta_{b}-\omega<\theta_{g}-\omega<\theta_{b}+\omega<\theta_{g}+\omega$.

Pries (2004) shows that the above assumptions give rise to an "all-or-nothing" learning process. With an observation of $x$ within $\left(\theta_{b}+\omega, \theta_{g}+\omega\right]$, the plant learns with certainty that it is a good plant; conversely, an observation of $x$ within $\left[\theta_{b}-\omega, \theta_{g}-\omega\right)$ indicates that it is a bad plant. However, an $x$ within $\left[\theta_{g}-\omega, \theta_{b}+\omega\right]$ does not reveal anything, since the probabilities of falling in this range as a good plant and as a bad plant are the same (both equal to $\frac{2 \omega+\theta_{b}-\theta_{g}}{2 \omega}$ ).

This all-or-nothing learning simplifies my model considerably. Since it is $\theta^{e}$ instead of $\theta$ that affects plants' decisions, there are three types of plants corresponding to the three values of $\theta^{e}$ : plants with $\theta^{e}=\theta_{g}$, plants with $\theta^{e}=\theta_{b}$, and plants with $\theta^{e}=\theta_{u}$, the prior mean of $\theta$. We define "unsure plants" as those with $\theta^{e}=\theta_{u}$. We further assume that the unconditional probability of $\theta=\theta_{g}$ is $\varphi$, and let $p \equiv \frac{\theta_{g}-\theta_{b}}{2 \omega}$ denote the probability of the true idiosyncratic productivity being 
revealed every period. Hence a plant's life-cycle is incorporated into the model as follows. A flow of new plants enter the market as unsure; thereafter, every period they stay unsure with probability $1-p$, learn they are good with probability $p \cdot \varphi$ and learn they are bad with probability $p \cdot(1-\varphi)$. The evolution of $\theta^{e}$ from the time of entry is a Markov process with values $\left(\theta_{g}, \theta_{u}, \theta_{b}\right)$, an initial probability distribution $(0,1,0)$, and a transition matrix

$$
\left(\begin{array}{ccc}
1 & 0 & 0 \\
p \cdot \varphi & 1-p & , \\
0 & 0 & 1
\end{array}\right)
$$

If plants were to live forever, eventually all uncertainty would be resolved because the market would provide enough information to reveal each plant's idiosyncratic productivity. The limiting probability distribution as $a$ goes to $\infty$ is $(\varphi, 0,(1-\varphi))$.

Because there is a continuum of plants, it is assumed that the law of large numbers applies, so that both $\varphi$ and $p$ are not only the probabilities but also the fractions of unsure plants with $\theta=\theta_{g}$, and of plants who learn $\theta$ each period, respectively. Hence, ignoring plant exit for now, the densities of the three groups of plants in a cohort of age $a$ as

$$
\left(\varphi \cdot\left[1-(1-p)^{a}\right], \quad(1-p)^{a}, \quad(1-\varphi) \cdot\left[1-(1-p)^{a}\right]\right)
$$

which implies an evolution of the idiosyncratic-productivity plant distribution within a birth cohort as shown in Figure 2, with the horizontal axis depicting the age of a cohort over time. The densities of plants that are certain about their idiosyncratic productivity, whether good or bad, grow as a cohort ages. Moreover, the two "learning curves" (depicting the evolution of densities of good plants and bad plants) are concave. This feature is defined as the decreasing property of marginal learning in Jovanovic (1982): the marginal learning effect decreases with plant age, which, in my model, is reflected by the fact that the marginal number of learners decreases with cohort age. The convenient feature of all-or-nothing learning is that, on the one hand, it implies that any single plant learns "suddenly", which allows us to easily keep track of the cross-section distribution of beliefs while, on the other hand, it still implies "gradual learning" at the cohort level.

\subsection{Plant Decisions and Industry Equilibrium}

We now turn to the supply and demand conditions in this model, and to the economics of creative destruction. Since our purpose is to model the age difference in plant-level labor demand, we assume perfectly elastic labor supply. This sub-section considers a recursive competitive (partial) equilibrium definition which includes as a key component the law of motion of the aggregate state of the industry. The aggregate state is $(F, D)$. $F$ denotes the distribution (measure) of plants across vintages and expected idiosyncratic productivity. $D$ is an exogenous demand parameter; it captures aggregate conditions and is fully observable. The law of motion for $D$, denoted $H_{D}$, is exogenous. The law of motion for $F$, denoted $H_{F}$, is such that $F^{\prime}=H_{F}(F, D)$. The part of $F$ that 
measures the number of plants with belief $\theta^{e}$ and age $a$ is denoted $f\left(\theta^{e}, a\right)$. The following sequence of events implies that $H_{F}$ captures the influence of entry, exit and learning:

First, entry and exit occur by observing the aggregate state. Second, each surviving plant adjusts its employment and produces. Third, the industry equilibrium price is realized. Fourth, plants observe revenue and update beliefs. Then, another period begins.

\subsubsection{Plant Employment Decision}

We assume costless employment adjustment each period. Accordingly, a plant adjusts its employment to solve a static profit maximization problem. With wage rate normalized as $1, \theta^{e}$ as a plant's current belief of its idiosyncratic productivity, and $P$ as the equilibrium price, a plant's employment is,

$$
\begin{aligned}
n\left(\theta^{e}, a\right) & =\underset{n_{t} \geq 0}{\arg \max } E\left[P \cdot A(a) \cdot x \cdot n^{\alpha}-n\right] \\
& =\left[\alpha \frac{P A \theta^{e}}{(1+\gamma)^{a}}\right]^{\frac{1}{1-\alpha}}
\end{aligned}
$$

, where $\theta^{e}$ can take on three values $\theta_{g}, \theta_{b}$ or $\theta_{u}$ as suggested by all-or-nothing learning process. And the corresponding expected plant-level output is

$$
q\left(\theta^{e}, a\right)=(\alpha P)^{\frac{\alpha}{1-\alpha}}\left(\frac{A \theta^{e}}{(1+\gamma)^{a}}\right)^{\frac{1}{1-\alpha}}
$$

The corresponding expected value of the single-period profit maximized with respect to $n_{t}$ is,

$$
\pi\left(\theta^{e}, a\right) \equiv\left(\alpha^{\frac{\alpha}{1-\alpha}}-\alpha^{\frac{1}{1-\alpha}}\right) \cdot\left[\frac{P A \theta^{e}}{(1+\gamma)^{a}}\right]^{\frac{1}{1-\alpha}}-\Psi
$$

$\Psi>0$ is the fixed operation cost each period. The value of $F$ is the same for all plants in the industry regardless of their vintages and idiosyncratic productivity.

\subsubsection{Plant Exit Decision}

A plant exits with negative expected value of staying. The exit decision of a plant is forwardlooking: plants have to form expectations about both current and future profits, based on its expected idiosyncratic productivity $\theta^{e}$, age $a$, and the aggregate state $(F, D)$. Let $V\left(\theta^{e}, a ; F, D\right)$ be the value of staying in the market for a plant with age $a$ and belief $\theta^{e}$. Then $V$ satisfies:

$$
\begin{aligned}
V\left(\theta^{e}, a ; F, D\right) & =\pi\left(\theta^{e}, a ; F, D\right)+\beta \cdot E\left\{\max \left[0, V\left(\theta^{e^{\prime}}, a+1 ; F^{\prime}, D^{\prime}\right)\right] \mid \theta^{e}, F, D\right\} \\
\text { subject to } & : \quad F^{\prime}=H_{F}(F, D), D^{\prime}=H_{D}(D)
\end{aligned}
$$

We assume that parameters are such that $V\left(\theta_{b}, a ; F, D\right)<0$ for any $a, F$ and $D$ : the expected value of staying of a bad plant at any age is always negative. Therefore, bad plants always exit. 
(2) suggests that $\pi\left(\theta^{e}, a ; F, D\right)$ decreases in $a$ : plants with older vintages are less profitable. It follows that, holding other parameters constant, $V\left(\theta^{e}, a ; F, D\right)$ also decreases in $a$. Therefore, each period there exists a maximum plant age for each $\theta^{e}$, denoted $\bar{a}\left(\theta^{e} ; F, D\right)$, so that plants with $\theta^{e}$ exit if they are older than $\bar{a}\left(\theta^{e} ; F, D\right)$.

\subsubsection{The Entry Size}

The industry features continual entry. To fix the size of entry, we further assume that each entrant has to pay an entry cost $c$ to enter the market, and $c$ satisfies

$$
c=c_{0}+c_{1} \cdot f^{\prime}\left(\theta_{u}, 0 ; F, D\right), \quad c>0, c_{1} \geq 0 .
$$

$f^{\prime}\left(\theta_{u}, 0 ; F, D\right)$ denotes the entry size with aggregate state $(F, D)$. We let the entry cost depend positively on the entry size to capture the idea that, for the industry as a whole, fast entry is costly and adjustment may not take place instantaneously. This can arise from a limited amount of land available to build production sites or an upward-sloping supply curve for the industry's specific capital. ${ }^{9}$ The free entry condition equates a plant's entry cost to its value of entry, and can be written as

$$
V\left(\theta_{u}, 0 ; F, D\right)=c_{0}+c_{1} \cdot f\left(\theta_{u}, 0 ; F, D\right)
$$

As more new plants enter, the entry cost is driven up until it reaches the value of entry. At this point, entry stops.

\subsubsection{Industry Equilibrium}

Let $Q(F, D)$ represent the industry-equilibrium output, A recursive competitive equilibrium in this industry is a law of motion $H_{F}$, a value function $V$, and a pricing function $P$ such that:

1. $V$ satisfies (3);

2. $F^{\prime}=H(F, D)$ is generated by the appropriate summing-up of plants' entry, exit, and learning. Let $f^{\prime}\left(\theta_{u}, 0 ; F, D\right)$ denote the part of $F^{\prime}$ that measures the number of plants with belief $\theta^{e}$ and age $a$,

$$
\begin{aligned}
f^{\prime}\left(\theta_{u}, 0 ; F, D\right) & =\frac{V\left(\theta_{u}, 0 ; F, D\right)-c_{0}}{c_{1}} \\
f^{\prime}\left(\theta_{u}, a ; F, D\right) & =(1-p) \cdot f\left(\theta_{u}, a-1\right) \text { for } 0<a \leq \bar{a}\left(\theta_{u} ; F, D\right) \\
f^{\prime}\left(\theta_{g}, a ; F, D\right) & =f\left(\theta_{g}, a-1\right)+p \varphi \cdot f\left(\theta_{u}, a-1\right) \text { for } 0<a \leq \bar{a}\left(\theta_{g} ; F, D\right) \\
f^{\prime}\left(\theta_{u}, a ; F, D\right) & =0 \text { for } a>\bar{a}\left(\theta_{u} ; F, D\right), \text { and } f^{\prime}\left(\theta_{g}, a ; F, D\right)=0 \text { for } a>\bar{a}\left(\theta_{g} ; F, D\right) .
\end{aligned}
$$

\footnotetext{
${ }^{9}$ See Goolsbee (1998) for related empirical evidence.
} 
3. $Q(F, D)$ equals the sum of all staying plants' output: ${ }^{10}$

$$
Q(F, D)=\sum_{a=0}^{\bar{a}\left(\theta_{g} ; F, D\right)} q\left(\theta_{g}, a ; F, D\right) \cdot f^{\prime}\left(\theta_{g}, a ; F, D\right)+\sum_{a=0}^{\bar{a}\left(\theta_{u} ; F, D\right)} q\left(\theta_{u}, a ; F, D\right) \cdot f^{\prime}\left(\theta_{u}, a ; F, D\right)
$$

4. $P(F, D)$ satisfies:

$$
P(F, D)=\frac{D}{Q(F, D)}
$$

Three essential parts capture the key component of the equilibrium - the law of motion for plant distribution $H_{F}$ : the entry size $f\left(\theta_{u}, 0 ; F, D\right)$, good plants' maximum age $\bar{a}\left(\theta_{g} ; F, D\right)$, and unsure plants' maximum age $\bar{a}\left(\theta_{u} ; F, D\right)$. These three parts, together with the all-or-nothing learning, update $F$ to $F^{\prime}$. $F^{\prime}$ gives the industry-equilibrium output and price by conditions 3 and 4 , and serves as part of the aggregate state for the next period.

\section{The Steady State: Plant Life Cycle and Job Flows}

In the model described above, new plants embodied with the latest technology keep coming in; the sizes of incumbents grow or shrink, depending on what they learn and how fast the technology updates; and those realized as bad plants or with outdated technology are continually being thrown out. Thus, the industry keeps retooling new technology and getting rid of bad plants, resulting in a reallocation process where labor flows into more productive units. This process is driven by two forces - learning and creative destruction.

Before exploring the response of the industry to demand fluctuations in Section 4, it is instructive to explore the job-flow patterns at the industry equilibrium when demand stays time-invariant.

\subsection{The Steady State}

We define a steady state as a recursive competitive equilibrium with time-invariant aggregate states: $D$ is and is perceived as time-invariant: $D=H_{D}(D) ; F$ is also time-invariant: $F=H_{F}(F, D)$. Since $H_{F}$ is generated by entry, exit and learning, a steady state must feature time-invariant entry and exit for $F=H_{F}(F, D)$ to hold. Thus, it can be summarized by $\left\{f^{s s}(0, D), \bar{a}_{u}^{s s}(D), \bar{a}_{g}^{s s}(D)\right\}$, with $f^{s s}(0, D)$ as the steady-state entry size, $\bar{a}_{g}^{s s}(D)$ as the maximum age for good plants, and $\bar{a}_{u}^{s s}(D)$ as the maximum age for unsure plants. The next proposition establishes the existence of a unique steady-state equilibrium.

Proposition 1: With constant $D$, there exists a unique time-invariant $\left\{f^{s s}(0, D), \bar{a}_{u}^{s s}(D), \bar{a}_{g}^{s s}(D)\right\}$ that satisfies the conditions (1) - (4); moreover, with constant $D$, the product of price and the most advanced technology, $P A$, remains time-invariant: $P A=\overline{P A}(D)$.

\footnotetext{
${ }^{10}$ Although industry-level output should equal the sum of realized plant-level output, it can be shown that the expectation error and the random noise cancel out within each age cohort so that the sum of expected plant output equals the sum of realized output.
} 


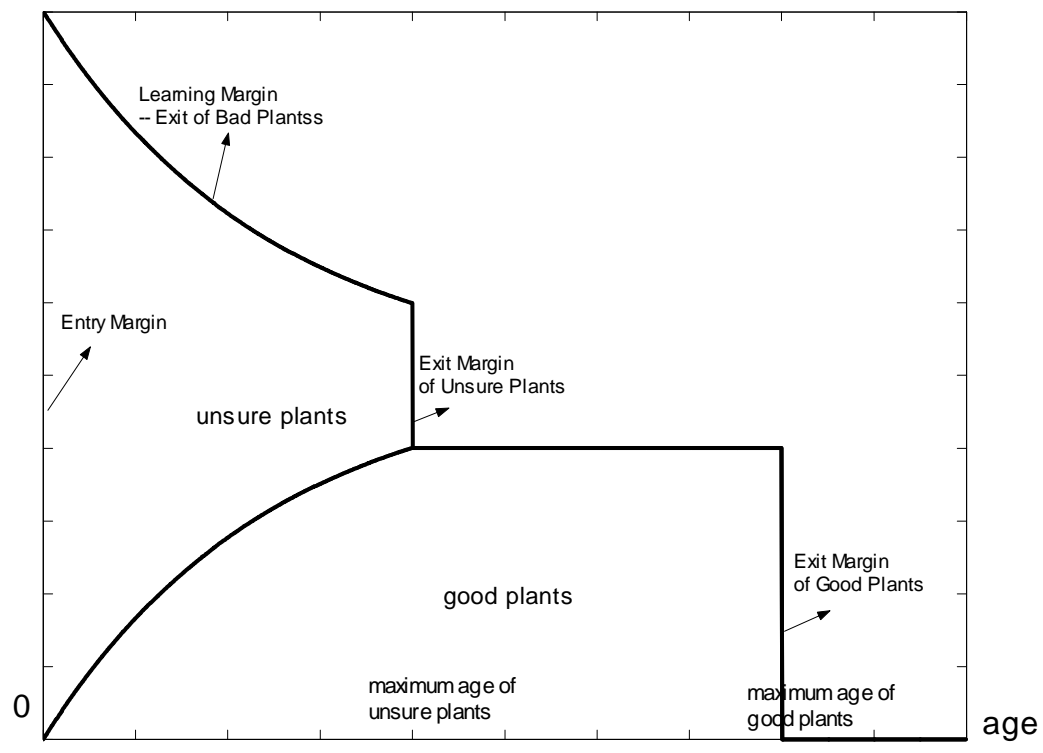

Figure 3: The Steady-state Plant Distribution across Ages and Expected Idiosyncratic Productivity, or Dynamics of a Birth Cohort with both Learning and Creative Destruction. the distance between the lower curve (extended as the horizontal line) and the bottom axis measures the density of good firms; the distance between the two curves measures the density of unsure firms.

See the appendix for proof. Proposition 1 suggests that a steady state features, (1) timeinvariant distribution of plants across ages and $\theta^{e} ;(2)$ time-invariant $P A$, as the product of price and the most advanced technology. Since $A$ grows exogenously at $\gamma$, the steady-state price $P$ must be declining at $\gamma$ for $P A$ to stay time-invariant. Put intuitively, entry continually brings in updated technology, while exit throws out outdated technology. Hence, the average technology level embodied in the industry grows over time. Growing technology increases the industry output, so that, holding demand constant, price declines over time.

With time-invariant entry size, at a steady state all cohorts start with the same size; as they age, they experience the same dynamics driven by learning; and plants with the same $\theta^{e}$ exit after the same age. Hence, the steady state plant distribution across ages and expected idiosyncratic productivity comes from the overlapping of different life stages of different birth cohorts. Figure 3, as Figure 1 truncated by the maximum ages of unsure and good plants, displays this distribution with the horizontal axis depicting plant age cross-section.

\subsubsection{The Plant Life Cycle}

This sub-section uses the model to assess the impact of plant life cycle on industry-level employment dynamics. Since industry-level employment dynamics are computed by aggregating the individual decisions of plants, we begin with the steady-state employment of a plant in operation, denoted 


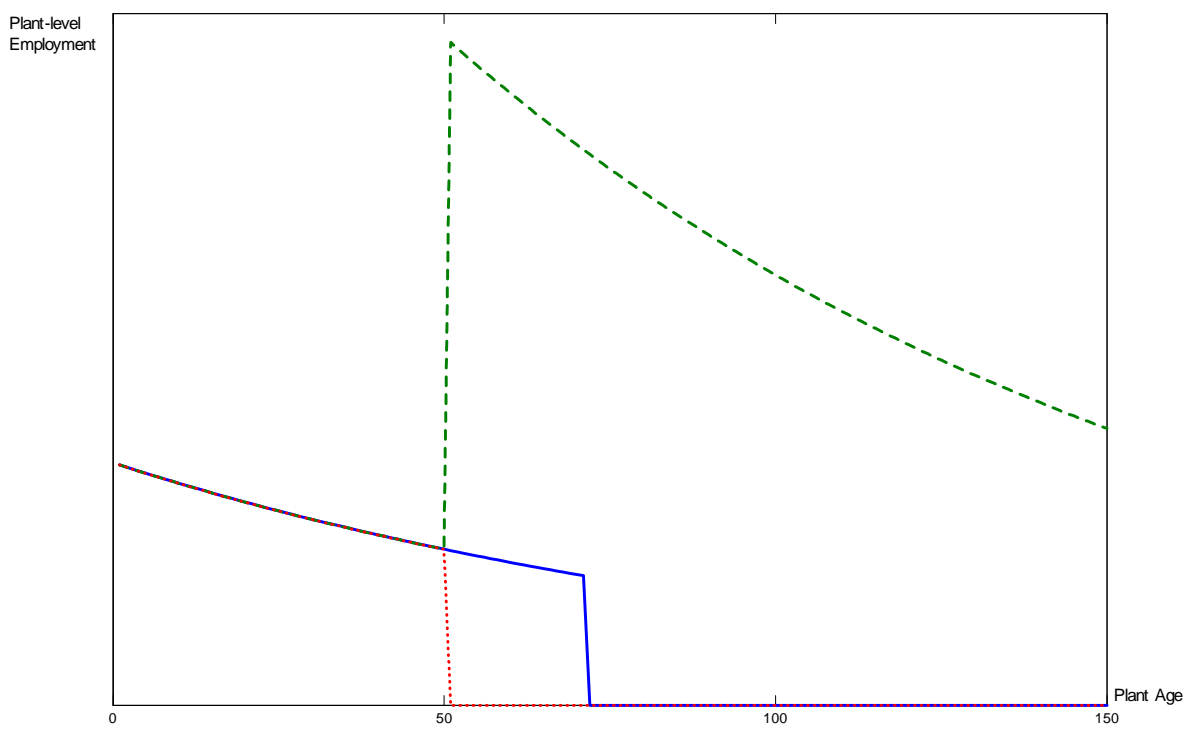

Figure 4: Employment Dynamics at Three Representative Plants: solid line plots the employment dynamics at an unsure plant that never learns and exit after 71 periods; dotted line plots those at a plant that learns it is a bad plant after 50 periods; dashed line plots those at a plant that learns it is a good plant after 50 periods and exit after 150 periods. This graph is generated by assuming $\theta_{g}=2.4, \theta_{b}=1, p=0.05, \varphi=0.5$, and $\gamma=0.003$. The steady-state solution corresponding to a demand level of 10000 for the exit age of good plants is 150 , for the exit age of an unsure plant is 71.

$n^{s s}:$

$$
n^{s s}\left(\theta^{e}, a ; D\right)=\left[\alpha \theta^{e} \frac{\overline{P A}(D)}{(1+\gamma)^{a}}\right]^{\frac{1}{1-\alpha}},
$$

where $a \leq \bar{a}_{u}^{s s}(D)$ when $\theta^{e}=\theta_{u}$, and $a \leq \bar{a}_{g}^{s s}(D)$ when $\theta^{e}=\theta_{g}$. Since $n^{s s}\left(\theta^{e}, a ; D\right)$ depends positively on belief $\theta^{e}$, a plant increases its employment (creates jobs) when it learns it is good, and exits (destroys jobs) once it learns it is bad. With age $a$ affecting $n^{s s}\left(\theta^{e}, a ; D\right)$ negatively, a plant decrease its employment (destroys jobs) as it grows older, and exits (destroys jobs) once it reaches its exit age according to its expected idiosyncratic productivity. We call the impact of $\theta^{e}$ on plant employment the learning effect, and that of a the creative destruction effect. These two effects interact together to drive plant-level and hence the aggregate employment dynamics.

Figure 4 captures the steady-state plant life cycle by presenting the employment dynamics of three representative plants, two of which assumed to learn at age 50: plant one stays unsure and exits after $\bar{a}_{u}^{s s}(D)$; plant two learns it is good and exits after $\bar{a}_{g}^{s s}(D)$; plant three learns it is bad and exits. The solid line, dashed line and the dotted line represent accordingly the employment dynamics of plant one, two and three. As Figure 4 shows, before age 50, all three plants destroy jobs continually due to the creative destruction effect; at age 50, plant one creates jobs but plant 
three destroys jobs by exit due to the learning effect; after age 50, plants one and two again destroy jobs continually; they exit after age $\bar{a}_{u}^{s s}(D)$ and $\bar{a}_{g}^{s s}(D)$.

\subsubsection{The Cohort Life Cycle}

To explore the cohort-level employment dynamics, again examine Figure 3 with the horizontal axis depicting cohort age across time. Like Figure 2, Figure 3 then represent a representative cohort's life-cycle dynamics. At age 0, it contains unsure plants only. As it ages, bad plants are thrown out and good plants are realized. After a certain age, all unsure plants exit because their vintage is too old to survive with $\theta^{e}=\theta_{u}$. However, plants with $\theta^{e}=\theta_{g}$ stay. Subsequently, the cohort contains only good plants and its size remains constant because learning has stopped. Eventually, the vintage of the cohort will be too old even for good plants to survive.

Furthermore, Figure 3 implies a job creation and destruction schedule over a cohort's life cycle. First, because all newly born plants begin with zero employment, they begin their lives by job creation. As they age, the learning effect drives job creation among plants that discover they are good, and drives job destruction among plants that discover they are bad. Meanwhile, the creative destruction effect drives aging plants that do not learn to destroy jobs. After $\bar{a}_{u}^{s s}(D)$, all unsure plants end their life by job destruction; so do all good plants after $\bar{a}_{g}^{s s}(D)$.

As we have elaborated in Section 2, the concave learning curves suggest that the marginal number of learners decreases as a cohort ages. It can be shown that, the fraction of plants that adjust their employment due to the learning effect, in an age- $a$ cohort, equals

$$
\begin{aligned}
\frac{p(1-p)^{a}}{(1-p)^{a}+\varphi\left[1-(1-p)^{a}\right]}, \text { for } 0 & \leq a \leq \bar{a}_{u}^{s s}(D) \\
0, \text { for } \bar{a}_{u}^{s s}(D) & <a \leq \bar{a}_{g}^{s s}(D),
\end{aligned}
$$

which decreases in $a$. This suggests that, as a cohort grows older, the learning effect weakens: fewer and fewer plants create or destroy jobs due to learning. Once all unsure plants have left after $\bar{a}_{u}^{s s}(D)$, learning stops completely.

On the contrary, the creative destruction effect strengthens with plant age. The fraction of plants that destroy jobs (including both decreasing employment level and exit) due to the creative destruction effect in an age- $a$ cohort equals

$$
\begin{aligned}
\frac{\varphi\left[1-(1-p)^{a}\right]+(1-p)^{a+1}}{\varphi\left[1-(1-p)^{a}\right]+(1-p)^{a}}, \text { for } 0 & \leq a<\bar{a}_{u}^{s s}(D) \\
1, \text { for } \bar{a}_{u}^{s s}(D) & <a \leq \bar{a}_{g}^{s s}(D)
\end{aligned}
$$

which increases in $a$. As a cohort grows older, more and more plants destroy jobs due to the creative destruction effect; furthermore, plants are more likely to exit (destroy jobs). At a certain age, all unsure plants destroy jobs by exit; as the remaining good plants grow older, eventually they destroy jobs too.

Although the employment dynamics driven by learning appears rather "sudden" at the plant 


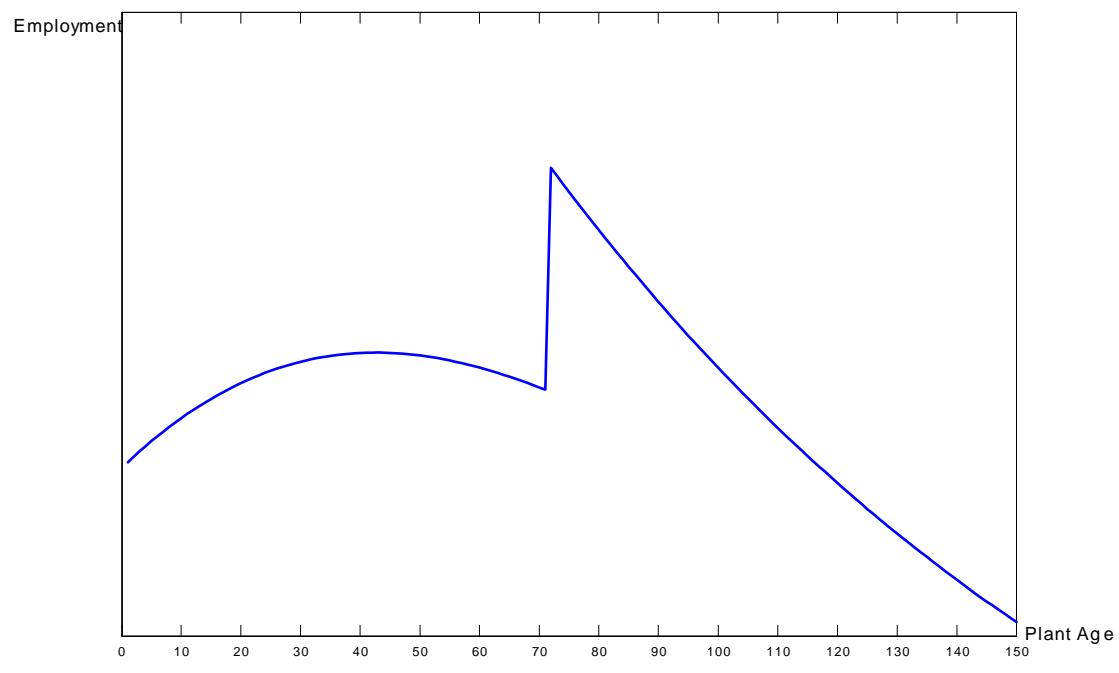

Figure 5: Average Plant-level Employment of A Birth Cohort: average plant-level employment equals the cohort-level employment divided by the number/measure of plants in this cohort; the steady-state parameter values and solutions are the same as in Figure 3.

level, as Figure 4 shows, it can be smoothed out at the cohort level by aggregating the adjustment of plants at the learning margin. If we add the employment of a good plant weighted by the fraction of good plants with that of an unsure plant weighted by the fraction of unsure plants at different ages, we get the life-cycle employment dynamics of an "average plant". This is plotted in Figure 5.

The "average plant" in Figure 5 increases its employment over time when it is very young, due to the strong learning effect. However, as it grows older and the learning effect weakens, the creative destruction effect begins to dominate: its employment begins to decrease after a certain age. At age $\bar{a}_{u}^{s s}(D)$, its employment jumps up because all the unsure plants exit at this age and the cohort contains only good plants. Afterward, this "average plant" keeps destroying jobs due to the creative destruction effect. It exits after $\bar{a}_{g}^{s s}(D)$.

\subsection{Aggregate Employment Dynamics}

The aggregate employment dynamics implied by our model reflect the number of plants choosing to adjust employment and the magnitude of their adjustment. In our model, demand have significant influences on both of these dimensions.

Again, consider Figure 3 with the horizontal axis depicting the plant age cross-section. Notice that, despite its time-invariant structure at the steady state, the industry experiences continuous entry, exit and learning. With entry, jobs are created; with exit, jobs are destroyed; with learning, jobs are either created or destroyed. From a pure accounting point of view, there are two margins for job creation - the entry margin and the learning margin where plants learn they are good - 
and four margins for job destruction - the exit margins of good and unsure plants, the learning margin where plants learn they are bad, and the margin where plants age with the same $\theta^{e}$.

Demand affects the number of plants at these margins. The next proposition relates demand to the entry size and the exit ages at the steady state.

Proposition 2: at a steady-state equilibrium, $f^{s s}(0, D), \bar{a}_{u}^{s s}(D)$ and $\bar{a}_{g}^{s s}(D)$ are all weakly increasing in $D$.

Detailed proof is presented in the Appendix. Proposition 3 suggests that, if we compare two steady-state equilibria, one with a high demand and the other with a low demand, the low-demand steady state features less entry and younger exit ages ( the exit ages in Figure 3 would shift left-ward ) .

If the above intuition carries over with probabilistic demand fluctuations, then a drop in demand would cause less entry, giving rise to a drop in job creation by young plants, and more exit, implying a jump in job destruction by old plants. Moreover, the impact of demand on the entry size suggests its influence on the number of plants at the learning margin. If entry size fluctuates with demand, birth cohorts may have started with different sizes, implying the size of a cohort of age $a$ depends on the level of demand $a$ periods ago. Hence, the past demand sequence affects the plant distribution across ages, and consequently, the number of plants at the learning margin since the fraction of learning plants differs in age.

Demand also influences the magnitude of plants' employment adjustment. According to Proposition 2, constant demand causes constant $P A$ because of the time-invariant industry structure. Above analysis has pointed out that, when demand fluctuates, the age distribution no longer stays time invariant. Hence, $P A$ must fluctuate with demand. Since the plant employment depends on $P A$ positively, an increase in $P A$ amplifies job creation but dampens job destruction; and a decrease in $P A$ dampens job creation but amplifies job destruction. Moreover, fluctuates in $P A$ create additional job-flow margins: continuing operating plants who do not learn or exit can create jobs when $P A$ increases, and destroy (more) jobs when $P A$ decreases, unlike their steady-state counter-parts who destroy jobs only. We call the impact of $P A$ on employment dynamics the demand effect.

Therefore, in our model, it is the interaction of the learning effect, the creative destruction effect, and the demand effect that drives the aggregate employment dynamics. Can our model possibly produce the observed age patterns of job flows in the U.S. manufacturing sector? Yes, it can. First, the learning effect weakens with plant age, suggesting that it can generate the observed negative relationship between plant age and the job-flow magnitude, as long as the learning effect is strong enough. Second, the interaction of the creative destruction effect and the demand effect causes entry fluctuations, suggesting a more volatile job creation by young plants, as well as shifts of exit margins, implying a more volatile job destruction by old plants. Hence, it can also produce the observed positive relationship between plant age and the relative destruction-to-creation volatility, with the appropriate strength of the creative destruction effect. The next section explore our model's implications on aggregate employment dynamics quantitatively. 


\begin{tabular}{|c|c|}
\hline Calibrated Parameters & value \\
\hline productivity of bad plants: $\theta_{b}$ & 1 \\
\hline productivity of good plants: $\theta_{g}$ & 2.4 \\
\hline quarterly technological pace: $\gamma$ & 0.007 \\
\hline quarterly discount factor: $\beta$ & 0.99 \\
\hline the elasticity of production w.r.t. labor: $\alpha$ & 0.66 \\
\hline entry cost parameter: $c_{0}$ & 0.405 \\
\hline persistence rate of demand: $\mu$ & 0.95 \\
\hline prior probability of being a good plant: $\varphi$ & 0.03 \\
\hline quarterly pace of learning: $p$ & 0.04 \\
\hline Operation cost per period: $\Psi$ & 1 \\
\hline High Demand: $D_{h}$ & 1000 \\
\hline Low Demand: $D_{l}$ & 950 \\
\hline
\end{tabular}

Table 2: Base-line Parameterization of the Model

\section{Quantitative Implications on Aggregate Employment Dynamics}

This section applies numerical techniques to analyze a stochastic version of our model in which the demand follows a two-state Markov process with values $\left[D_{h}, D_{l}\right]$ and transition probability $\mu$. Throughout this section, plants expect the current demand level to persist for the next period with probability $\mu$, and to change with probability $1-\mu$.

We calibrate our model so that its equilibrium job-flow rates mimics the observed pattern in the data. Our calibration strategy is as follows. Since learning effect is most prominent among younger plants, we use young manufacturing plants' job creation and destruction rates to calibrate the two learning parameters: the quarterly learning pace $(p)$ and the prior probability of being a good plant $(\varphi)$. The rest of the parameters are calibrated to match the observed job-flow rates for the total manufacturing.

\subsection{Baseline Calibration}

Table 2 presents the assigned parameter values. Some of the parameter values are pre-chosen. We allow a period to represent one quarter and set the quarterly discount factor $\beta=0.99$. $\mu$ is chosen to equal 0.95 so that demand switches between a high level and a low level with a constant probability 0.05 per period. With a period as a quarter, a given demand will persist for five years on average, consistent with business cycle frequencies. ${ }^{11}$ The per-period fixed operation cost, $\Psi$, is set equal to 1 . As a matter of fact, as equation (14) in the appendix shows, $\Psi$ matters only as a scaler for demand. The elasticity of production with respect to labor input, $\alpha$, is approximately equal to the share of output paid to labor. We set $\alpha$ to 0.66. In a model with only creative destruction, Caballero and Hammour (1994) choose the quarterly technological growth rate as 0.007 by attributing all output growth of US manufacturing from the second quarter of 1972 to the fourth quarter of 1983 to technical progress. To make comparison with their results convenient

\footnotetext{
${ }^{11}$ See Barlevy (2002).
} 
in the coming subsections, we also choose $\gamma=0.007 . c_{0}=0.405$ and $c_{1}=0.52$ also come from Caballero and Hammour (1994), who estimate the entry cost function by matching the job creation series of US manufacturing from 1970 to 1989. The relative productivity of good and bad plants are chosen by following Davis and Haltiwanger (1999), who assume a ratio of high-to-low productivity of 2.4 based on the between-plant productivity differentials reported by Bartelsman and Doms (1997). We normalize productivity of bad plants as 1 and set productivity of good plants as 2.4.

We calibrate the prior probability of being a good plant $(\varphi)$ and the quarterly pace of learning $(p)$ by matching the observed young plants' job creation and destruction rate in the U.S. manufacturing sector. Let $j c \_y$ denote young plants' job creation rate, $j d \_y$ their job destruction rate, and $n\left(a, \theta^{e}\right)$ the employment level at an age- $a$ plant with expected idiosyncratic productivity $\theta^{e}$. Since young plants are defined as those younger than 40 quarters, it can be shown that

$$
j c_{-} y=\frac{\sum_{a=0}^{a=39} p \varphi(1-p)^{a}\left[n\left(a+1, \theta_{g}\right)-n\left(a, \theta_{u}\right)\right]}{\sum_{a=0}^{a=40}\left\{(1-p)^{a} n\left(a, \theta_{u}\right)+\varphi\left[1-(1-p)^{a}\right] n\left(a, \theta_{g}\right)\right\}}
$$

and

$$
j d_{-} y=\frac{\sum_{a=0}^{a=39}\left\{\begin{array}{c}
p(1-\varphi)(1-p)^{a} n\left(a, \theta_{u}\right)+ \\
(1-p)^{a+1}\left[n\left(a, \theta_{u}\right)-n\left(a+1, \theta_{u}\right)\right]+ \\
\varphi\left[1-(1-p)^{a}\right]\left[n\left(a, \theta_{g}\right)-n\left(a+1, \theta_{g}\right)\right]
\end{array}\right\}}{\sum_{a=0}^{a=40}\left\{(1-p)^{a} \cdot n\left(a, \theta_{u}\right)+\varphi \cdot\left[1-(1-p)^{a}\right] \cdot n\left(a, \theta_{g}\right)\right\}}
$$

Table 1 shows that in the U.S. manufacturing sector, young plants' job creation rate equals $7.52 \%$ on average, and their job destruction rate has a mean of $6.56 \%$. With other parameter values chosen as in Table $2, j c \_y \approx 7.52 \%$ and $j d \_y \approx 6.56 \%$ suggest that $p=0.04$ and $\varphi=0.03$.

Now the remaining parameters are $D_{h}$, high demand, $D_{l}$, low demand. Their values are chosen so that the job destruction series in the calibrated model matches properties of the historical series from the entire U.S. manufacturing sector. Davis and Haltiwanger (1999) show that the U.S. manufacturing job destruction rates from the second quarter of 1972 to the fourth quarter of 1993 fluctuates between $2.96 \%$ and $11.60 \%$ with a mean of $5.6 \%$. This put the following restrictions on our calibrated model.

First, its implied long-run job destruction rate must be around $5.6 \%$. We let $\overline{a_{g}}$ and $\overline{a_{u}}$ represent the maximum ages of good plants and unsure plants at the high-demand steady state and $\overline{a_{g}}$ and ${\overline{a_{u}}}^{\prime}$ represent the exit ages at the low-demand steady state. The steady-state job destruction rate implied by either pair, has to be around $5.6 \%$.

Second, we match the peak in job destruction that occurs at the onset of a recession. Our model suggests that the jump in the job destruction rate at the beginning of a recession comes from the shift of exit margins to younger ages. We assume that when demand drops, the exit margins shift from $\overline{a_{g}}$ and $\overline{a_{u}}$ to ${\overline{a_{g}}}^{\prime}$ and $\overline{a_{u}}$ 'immediately, and the job destruction rate at this moment must not 
exceed $11.6 \% .^{12}$

Third, we match the trough in job destruction that occurs at the onset of a boom. Our model suggests that when demand goes up, the exit margins extend to older ages, so that for several subsequent periods job destruction comes only from the learning margin, implying a trough in the job destruction rate. To match the data, the job destruction rate at this moment has to be around $3 \%$.

Additionally, $\left(\overline{a_{g}}, \overline{a_{u}}\right)$ and $\left({\overline{a_{g}}}^{\prime},{\overline{a_{u}}}^{\prime}\right)$ must satisfy steady state conditions on the gap between the exit ages of good and unsure plants; and the value of the fixed operation cost, must ensure our assumption that the expected value of staying for bad plants stays negative while the expected value of entry stays positive to ensure continuous entry. Using a search algorithm, we find that these conditions are satisfied for the following combination of parameter values: $\overline{a_{g}}=78, \overline{a_{u}}=64$, ${\overline{a_{g}}}^{\prime}=73,{\overline{a_{u}}}^{\prime}=59$. By applying these $\overline{a_{g}}, \overline{a_{u}}, \overline{a_{g}}$ ' and ${\overline{a_{u}}}^{\prime}$ to the steady state industry structure, we find $D_{h} \approx 1000$ and $D_{l} \approx 950$.

\subsection{Aggregate Employment Fluctuations}

With all of the parameter values assigned, we approximate plants' value functions. Our key computational task is to map $F$, the plant distribution across ages and idiosyncratic productivity, given demand level $D$, into a set of value functions $V\left(\theta^{e}, a ; F, D\right)$. Unfortunately, the endogenous state variable $F$ is a high-dimensional object. The numerical solution of dynamic programming problems becomes increasingly difficult as the size of the state space increases. Our computational strategy follows Krusell and Smith (1998) by shrinking the state space into a limited set of variables and showing that these variables' laws of motion can approximate the equilibrium behavior of plants in the simulated time series. The appendix presents the details. The approximated laws of motion suggests that the dynamic system is globally stable: the industry structure eventually settles down with constant entry and exit along any sample path where the demand level is unchanging. With the corresponding decision rules and an initial plant distribution, we can then investigate the aggregate time series properties of employment fluctuations in the calibrated model.

\subsubsection{Simulation Statistics from Baseline Calibration}

We start with a random plant distribution across ages and idiosyncratic productivity, simulate the model for 10000 periods according to the approximated value functions, and discard the first 500 periods to investigate the property of the stationary region of the simulated time series. Table 3 reports the statistics of the simulated job flows from the calibrated model. The sample statistics for the U.S. manufacturing job flows from the second quarter of 1972 to the fourth quarter of 1988 are included from comparison. Figure 6 presents a 87-period time series randomly chosen from our

\footnotetext{
${ }^{12}$ As I have noted earlier, the calibration exercises suggest that when a negative aggregate demand shock strikes, the exit margins shift more than ${\overline{a_{g}}}^{\prime}$ and ${\overline{a_{u}}}^{\prime}$. The bigger shift implies a bigger jump in job destruction, This is why I require $n e g_{\max }$ to lie below $11.60 \%$. I experiment with different demand levels to find those that generate the closest fit.
} 


\begin{tabular}{|l|cccc|}
\hline \multicolumn{5}{|c|}{ A. Data } \\
\hline Plant type & Mean $(C)$ & Mean $(D)$ & Emp.Share & $\frac{\operatorname{Var}(D)}{\operatorname{Var}(C)}$ \\
\hline all & 5.20 & 5.53 & 100 & 3.49 \\
\hline young & 7.52 & 6.56 & 22 & 1.32 \\
\hline old & 4.54 & 5.24 & 78 & 4.18 \\
\hline \multicolumn{5}{|c|}{ B. Simulation Statistics } \\
\hline Plant type & Mean $(C)$ & Mean $(D)$ & Emp.Share & $\frac{\operatorname{Var}(D)}{\operatorname{Var}(C)}$ \\
\hline all & 4.66 & 5.22 & 100 & 1.66 \\
\hline young & 7.31 & 6.20 & 60 & 1.51 \\
\hline old & 0.55 & 3.70 & 40 & 3.57 \\
\hline
\end{tabular}

Table 3: Quarterly gross job flows and employment share of young and old plants in the US manufacturing sector (1972 II to 1988 IV) and in the calibrated model: C denotes job creation, D job destruction, All numbers are in percentage points.

\begin{tabular}{|l|ccccc|}
\hline \multicolumn{7}{|c|}{ A. Data } \\
\hline Plant type & Mean $(C b)$ & Mean $(\mathbf{C c})$ & $\operatorname{Mean}(D d)$ & Mean $(\mathbf{D c})$ & $\frac{\operatorname{Var}(D c)}{\operatorname{Var}(C c)}$ \\
\hline all & 0.42 & $\mathbf{4 . 7 7}$ & 0.64 & $\mathbf{4 . 8 9}$ & $\mathbf{3 . 6 4}$ \\
\hline young & 1.52 & $\mathbf{6 . 0 0}$ & 1.24 & $\mathbf{5 . 3 3}$ & $\mathbf{2 . 8 0}$ \\
\hline old & 0.12 & $\mathbf{4 . 4 2}$ & 0.47 & $\mathbf{4 . 7 7}$ & $\mathbf{3 . 6 9}$ \\
\hline \multicolumn{7}{|c|}{ B. Simulation Statistics } \\
\hline Plant type & Mean $(C b)$ & Mean $(\mathbf{C c})$ & Mean $(D d)$ & Mean $(\mathbf{D c})$ & $\frac{\operatorname{Var}(D c)}{\operatorname{Var}(C c)}$ \\
\hline all & 3.07 & $\mathbf{1 . 5 9}$ & 2.40 & $\mathbf{2 . 8 3}$ & $\mathbf{3 . 1 4}$ \\
\hline young & 5.06 & $\mathbf{2 . 2 6}$ & 3.00 & $\mathbf{3 . 2 1}$ & $\mathbf{1 . 6 5}$ \\
\hline old & 0 & $\mathbf{0 . 5 5}$ & 1.45 & $\mathbf{2 . 2 5}$ & $\mathbf{5 . 1 7}$ \\
\hline
\end{tabular}

Table 4: Quarterly gross job flows from plant birth, plant death, and continuing operating plants in the US manufacturing sector (1972 II to 1988 IV) and in the simulations of the calibrated model. $\mathrm{Cb}$ denotes job creation from plant birth, Dd job destruction from plant death, Cc and Dc job creation and destruction from continuing operating plants. $\mathrm{C}$ and $\mathrm{D}$ represent gross job creation and destruction. $\mathrm{C}=\mathrm{Cc}+\mathrm{Cb}, \mathrm{D}=\mathrm{Dd}+\mathrm{Dc}$. All numbers are in percentage points. 

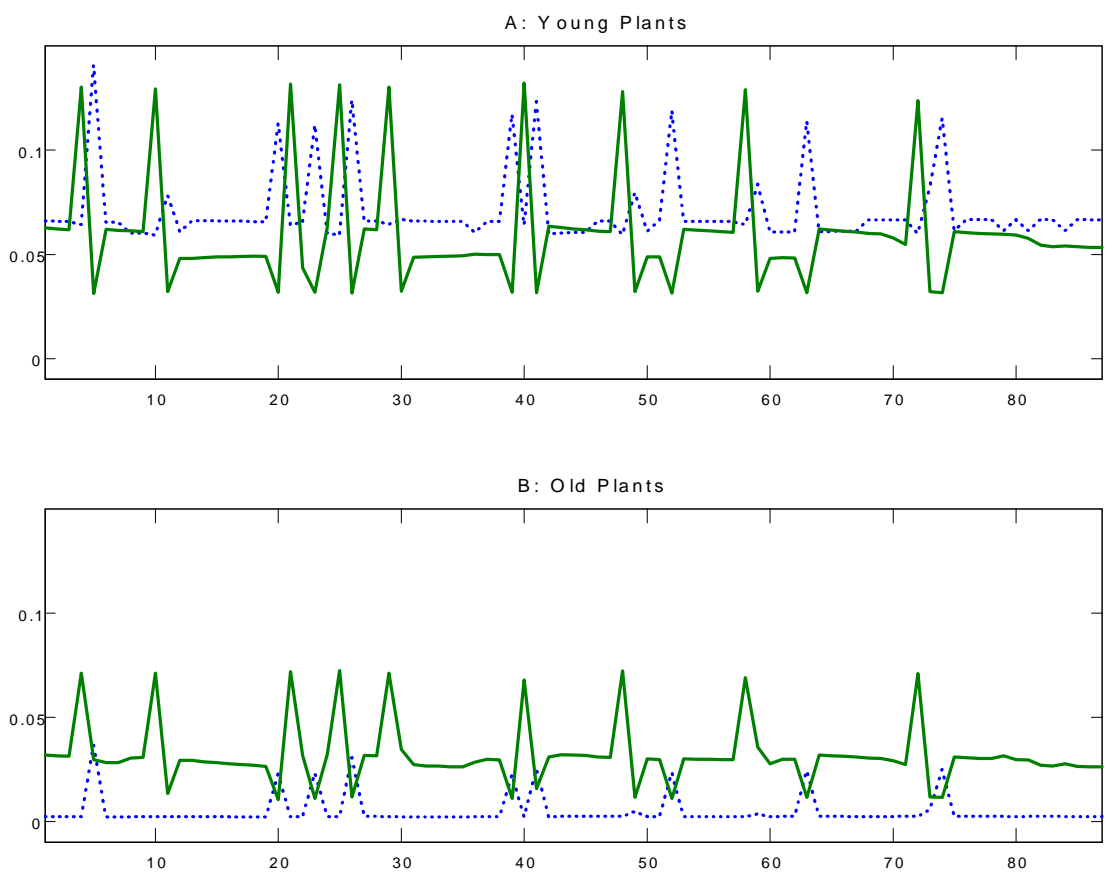

Figure 6: Simulated Job Flows at Young and Old Plants: soline lines represent job destruction and dotted lines job creation; the 87-period series are chosen randomly from the simulations. 
simulations.

The results in Table 3 suggest that the calibrated model can explain the observed relationship between plant age and job-flow magnitudes and variability: the mean job flow rates decline with plant age; and the relative volatility of job destruction to job creation increases with plant age. The suggested variance ratio of job destruction to job creation rates for young plants in the calibrated model matches that in the data closely: 1.51 compared to 1.32. The calibrated model also suggests a job destruction-to-creation variance ratio of 3.57 for old plants, close to the observed 4.18 in the data. This is further confirmed in Figure 6: the simulated old plants' job-flow series are positioned lower (display smaller means); furthermore, the volatility of destruction and creation for young plants appear much more symmetric.

Davis and Haltiwanger (1999) also documents that, even with the contributions of entering and exiting plants excluded, the relationship between plant age and job-flow magnitude and volatility is still evident. Table 4 compares the documented statistics from the US manufacturing sector with our simulated statistics of job flows due to plant birth, plant death, and continuing operating plants. As shown in Table 4, our calibrated model reproduces, at least qualitatively, the relationship between plant age and the magnitudes and variability of continuing operating plants: their mean job-flow rates decline with plant age, and their relative volatility of destruction and creation increases with plant age.

However, in both Table 3 and Table 4 the mean job flow rates for old plants in the calibrated model are significantly smaller than those in the data. This comes both from our model's vintage feature and from our calibration strategy. As described in Sub-section 4.1, our calibration strategy was, firstly, to calibrate the value of $p$ and $\varphi$ by matching the job flow rates of young plants, and then to calibrate other parameter values by matching the job flow rates for all plants. Notice that, because of their better vintages, young plants in our model hire more labor and hence have a higher employment share - as shown in the "emp. share" column of Table 3, they account for $60 \%$ of total employment while, in the data, they account for only $22 \%$ of total employment on average over the sample period. Our model's higher employment share of young plants put more weight on their higher job flow rates, so that, the job flow magnitude of old plants have to be significantly smaller in order to match the observed job-flow magnitude of all plants. For the same reason, the variance ratio of job destruction to job creation of all plants in the calibrated model is closer to that of young plants with a value of 1.66. But in the data, since old plants account for $78 \%$ of total employment, their variance ratio of 4.18 gives a variance ratio of 3.49 for all plants, implying a more volatile job destruction rate.

\subsubsection{Plant Age and the Relative Volatility of Job Destruction and Creation}

According to the analysis in Section 3, learning and creative destruction effects together drive the job flows in our model; when demand fluctuates, aggregate employment fluctuations come from these two effects' interaction with the demand effect. Moreover, it is the creative destruction effect

that makes job creation among young plants but job destruction among old plants more volatile, so 


\begin{tabular}{|l|ccc|}
\hline plant type & Learning Effect & Demand Effect & Creative Destruction Effect \\
\hline Young & 9.2456 & 3.0970 & 0 \\
\hline Old & 9.9599 & 3.1267 & inf \\
\hline
\end{tabular}

Table 5: Simulated Variance Ratio of Job Destruction to Job Creation Driven by Learning Effect, Price Effect, and Creative Destruction Effect in the Baseline Calibration.
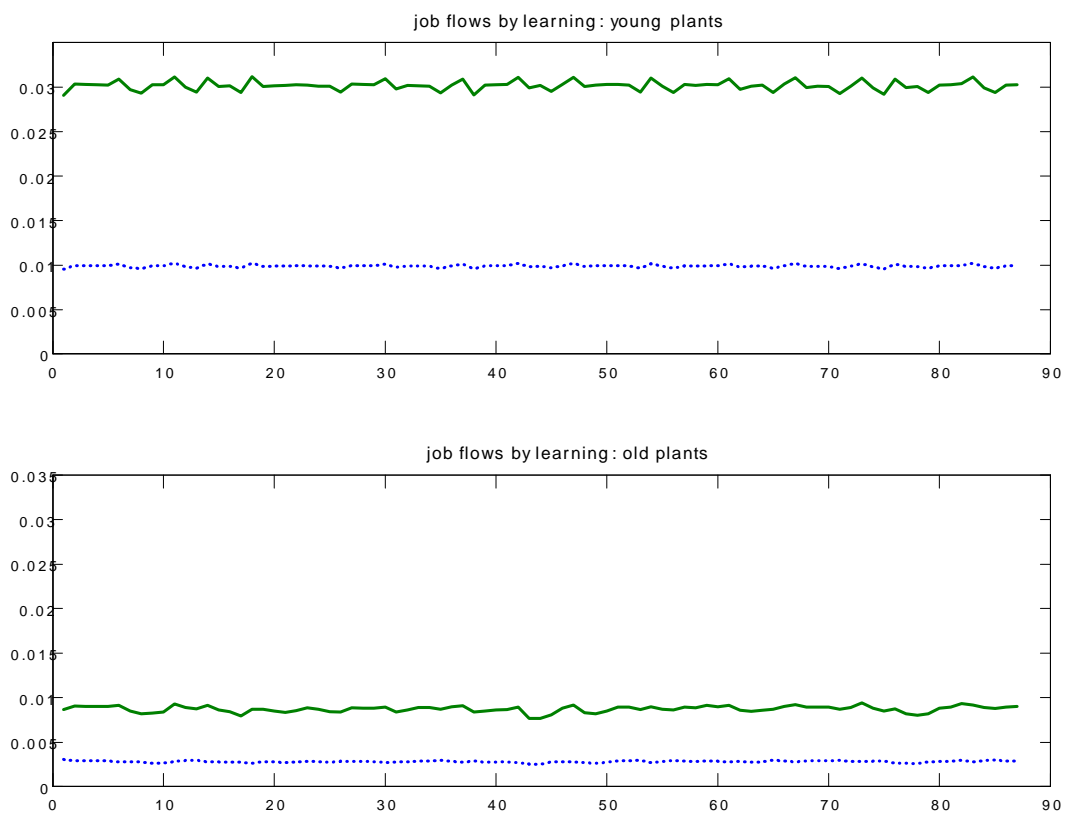

Figure 7: Simulated Job Flows Under the Learning Effect at Young and Old Plants

that the relative volatility of job destruction to creation increases with plant age. Since simulations from the calibrated model have reproduced this pattern, now we separate the variance ratio of job destruction and creation from the learning effect, the creative destruction effect, and the demand effects in our simulations to the explore which of the three effects has contributed to this pattern. The results are reported in Table 5 .

In Table 5, the simulated destruction-to-creation variance ratio under the creative destruction effect is 0 for young plants but inf for old plants. ${ }^{13}$ But under either the learning effect or the demand effect, the variance ratio are approximately the same for young and old plants. This concludes that, in the calibrated model, it must be the creative destruction effect that contributes to the different relative volatility of destruction and creation among young and old plants.

This is confirmed in Figures 7, 8 and 9, which present 87-period time series of job flow rates among young and old plants chosen randomly from our simulations driven by the learning effect,

\footnotetext{
${ }^{13}$ This is because the creative destruction effect drives new vintages to join young plants and old vintages to leave old plants. Since entry contributes to job creation but exit leads to job destruction, the creative destruction only contributes to the volalitity of creation among young plants and that of destruction among old plants.
} 

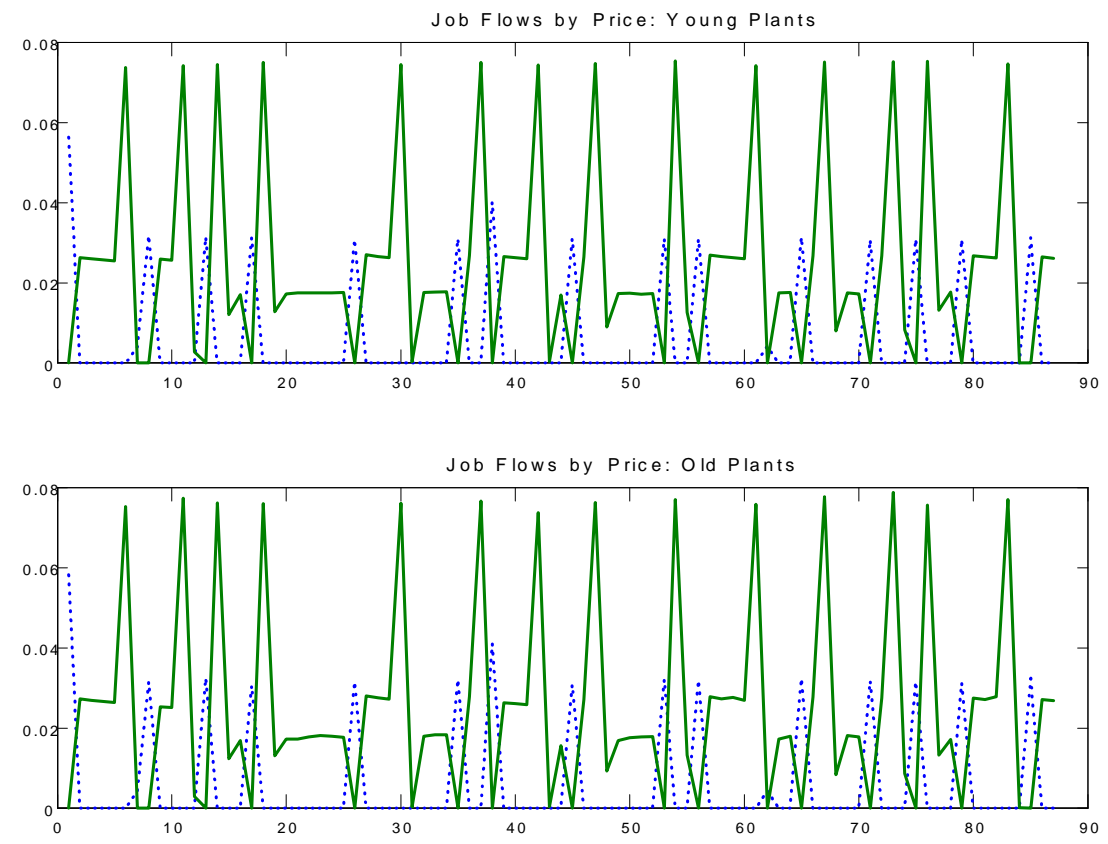

Figure 8: Simulated Job Flows Under the Price Effect at Young and Old Plants.

the demand effect, and the creative destruction effect. In Figure 7, job creation and destruction series driven by learning effect display similar relative volatility at young and old plants. So do those driven by the demand effect shown in Figure 8. Figure 9 presents the job flow series driven by the creative destruction effect, under which there is no job destruction among young plants or creation among old plants.

Two remarks should be made before we move to the next sub-section. First, in Table 5 and Figure 7, the destruction-to-creation variance ratio driven by the learning effect is significantly above one, suggesting that, in our model, the learning effect drives a more volatile job destruction margin. This is due to the calibrated value for $\varphi$ (the prior probability of being a good plant). Its value of 0.04 suggests that, every period $96 \%$ of the learning plants learn they are bad and exit (destroy jobs) but only $4 \%$ learn they are good and increase employment (create jobs). Therefore, more learning plants are at the destruction margin so that, when demand fluctuates, job destruction by learning fluctuates more. Second, under the demand effect, job destruction also appears more volatile. To understand why, notice that, a decrease in $P A$ drives job destruction by the demand effect only; an increase in $P A$ drives job creation by the demand effect only. Since $n_{t}\left(\theta^{e}, a\right)=\left[\alpha \theta^{e} \frac{P A_{t}}{(1+\gamma)^{a}}\right]^{\frac{1}{1-\alpha}}$, job destruction by the demand effect is amplified by $\frac{1}{1+\gamma}$ but job creation by the demand effect is dampened by $\frac{1}{1+\gamma}$. In another word, under the demand effect, job creation and destruction both fluctuate between zero and some value above zero; but when job destruction goes above zero (with a decline in $P A$ ), it increases by more. Hence, the demand effect also drives a more volatile 

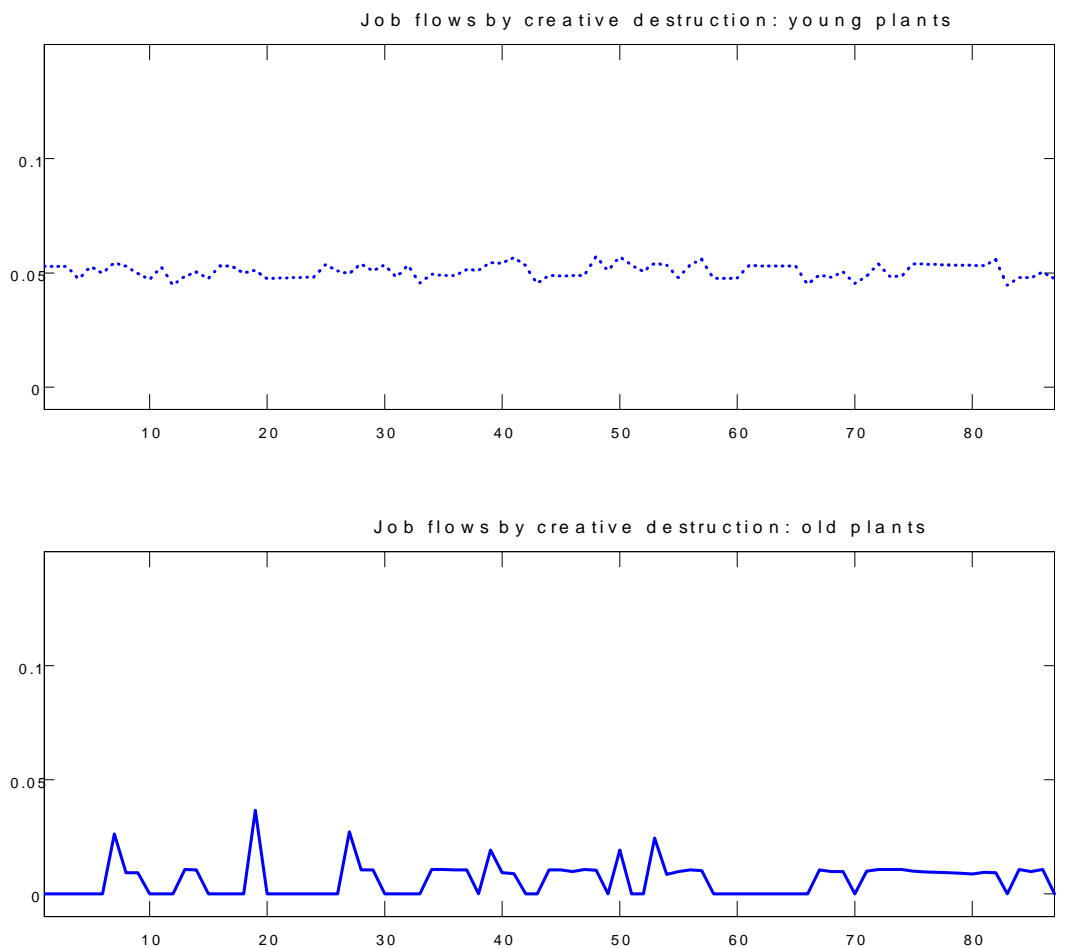

Figure 9: Simulated Job Flow Series Under the Creative Destruction Effect at Young and Old Plants. 


\begin{tabular}{|l|cccc|}
\hline \multicolumn{5}{|c|}{ A. Additional Calibration } \\
\hline Plant type & Mean $(C)$ & Mean $(D)$ & Emp.Share & $\frac{\operatorname{Var}(D c)}{\operatorname{Var}(C c)}$ \\
\hline all & 4.33 & 4.27 & 100 & 1.22 \\
\hline young & 7.66 & 6.36 & 56 & 1.19 \\
\hline old & 0.62 & 2.22 & 44 & 1.48 \\
\hline \multicolumn{5}{|c|}{ B. Baseline Calibration } \\
\hline Plant type & Mean $(C)$ & Mean $(D)$ & Emp.Share & $\frac{\operatorname{Var}(D c)}{\operatorname{Var}(C c)}$ \\
\hline all & 4.66 & 5.22 & 100 & 1.66 \\
\hline young & 7.31 & 6.20 & 60 & 1.51 \\
\hline old & 0.55 & 3.70 & 40 & 3.57 \\
\hline
\end{tabular}

Table 6: Job-flow Statistics from Baseline Calibration and Additional Calibration.

destruction margin, at both young and old plants.

\subsubsection{Strength of the Learning and Creative Destruction Effects: Additional Cali- bration}

There are three key parameters in our calibration exercises: $\gamma$, the technological pace; $p$, the learning pace; and $\varphi$, the prior probability of being a good plant. Notice that the all-or-nothing learning models $p \equiv \frac{\theta_{g}-\theta_{b}}{2 \omega}$, so that holding $\theta_{g}$ and $\theta_{b}$ constant, $p$ also reflects the value of $\omega-$ the noisiness of learning. This subsection uses different value combination of these three parameters to match the observed job reallocation rates, and check the sensitivity of our results.

The baseline parameterization follows Caballero and Hammour (1994) in setting the quarterly technological pace $\gamma$ equal to 0.007 . The value was estimated by attributing all output growth of the U.S. manufacturing sector to technological progress, which may exaggerate the technological pace in the relevant period. An alternative estimate of $\gamma$, has been provided by Basu, Fernald and Shapiro (2001), who estimate TFP growth for different industries in the U.S. from 1965 to 1996 after controlling for employment growth, factor utilization, capital adjustment costs, quality of inputs and deviations from constant returns and perfect competition. They estimate a quarterly technological pace of 0.0037 for durable manufacturing, a pace of 0.0027 for non-durable manufacturing and an even slower pace for other sectors.

How would a slow pace of technological progress affect the relative volatility of destruction and creation at young and old plants? To address this question, we re-calibrate our model assuming $\gamma=0.003$, matching young plants' job flow rates as before, and simulate responses of the recalibrated model. The results are presented in Table 5 together with results from the baseline parameterization.

The calibration results in Table 5 suggest that the model with $\gamma=0.003$ needs a faster learning pace ( $p=0.06$ compared to 0.04 , from the all of nothing learning process, a higher $p$ also suggests lower $\omega$ : a less noisy learning) to match the observed magnitude of young plants' job flows. The 
simulated job-flow series suggest that slower technological progress increases old plants' employment share ( $44 \%$ compared to $40 \%$ in the baseline calibration), and more importantly, bring the relative volatility of destruction and creation at young and old plants much closer ( 1.19 and 1.48, compared to 1.51 and 3.57 in the baseline calibration).

This result can be explained as follows. First, slower technological progress implies that the force of creative destruction is weak. A lower $\gamma$ weakens the technical disadvantage of old plants and allows both good plants and unsure plants to live longer, so that employment share of old plants increases. Second, when we assume a lower $\gamma$, we must also assume a higher $p$ and a lower $\varphi$ to match the observed magnitude of job flows. This re-calibration implies a stronger learning effect: plants not only learn faster, but are more likely to learn that they are bad. As argued already, young and old plants in our model have similar relative volatility of destruction and creation under the learning effect; it is the creative destruction effect that makes the destruction and creation margin respond differently at young and old plants. Therefore, a weak creative destruction effect and a strong learning effect together bring the relative volatility of destruction and creation at young and old plants closer.

Moreover, with a lower $\gamma$, the responses of job creation and destruction under the price effect become more symmetric. A slower technological pace weakens both its dampening effect on the volatility of job creation and its amplifying effect on the volatility of job destruction. This also contributes to the closer relative destruction-to-creation volatility at young and old plants.

\section{Conclusion}

Previous studies have pointed out two directions for theoretical models on gross job flows. First, large and pervasive job flows exist in very narrowly defined industries, reflecting the importance of heterogeneous labor demand at the plant level. Second, job-flow patterns differ significantly by plant age in both magnitudes and cyclical responses, suggesting the link between plant life cycle and aggregate employment dynamics. This paper proposes a theory motivated by those findings.

In our theory, job flows are driven by the learning and the creative destruction forces. The strengths of the two forces change as plants grow older, so that the resulting job-flow patterns differ significantly over plants' life cycle. Our theory is able to match two salient facts on manufacturing job flows: job flow rates are larger at younger plants; job destruction appears much more volatile than job creation at older plants, but at younger plants, their responses are nearly symmetric.

It is the productivity decomposition in our model that gives rise to the learning and creative destruction forces. We decompose plant-level productivity into a vintage component and an observable but learnable idiosyncratic component, to reflect the documented plant productivity dynamics in the U.S. manufacturing sector. Hence, with a model of plant life cycle, this paper suggests that evidence on plant-level employment dynamics and productivity dynamics can be reconciled.

There are many questions that can be explored in the future with this model. For example, labor reallocation has been documented to concentrate during recessions; but is the intense reallocation 
during recessions productivity enhancing? Such a question has been explored in Ouyang (2006) under a similar framework as in this paper. Furthermore, Kydland and Prescott (1982) argue that a representative-agent real business cycle model with technological shocks can account for most of the observed aggregate fluctuations. However, later empirical work by Basu (2005) suggests that the technological residual interacts very little with output and input sequences once we control for increasing returns, cyclical utilization and resource reallocation. Can a heterogeneous-agent model with resource reallocation, as the one in this paper, reconcile these papers by showing that the cyclical resource reallocation is a natural response of the economy to technological shocks? We believe there are many benefits to be gained from answering this question. The resulting findings will undoubtedly allow economists to learn more about the sources and consequences of business cycles. 


\section{Appendix}

Proof. According to steady-state demand condition,

$$
D=(P A)^{\frac{1}{1-\alpha}}\left\{\begin{array}{c}
\bar{a}_{u=0}^{\bar{a}_{u}^{s s}(D)} f^{s s}\left(\theta_{u}, a ; D\right) \alpha^{\frac{\alpha}{1-\alpha}}\left[\frac{\theta_{u}}{(1+\gamma)^{a}}\right]^{\frac{1}{1-\alpha}}+ \\
\bar{a}_{g}^{s s}(D) \\
\sum_{a=0}^{s s} f^{s s}\left(\theta_{g}, a ; D\right) \alpha^{\frac{\alpha}{1-\alpha}}\left[\frac{\theta_{g}}{(1+\gamma)^{a}}\right]^{\frac{1}{1-\alpha}}
\end{array}\right\} .
$$

, where $f^{s s}\left(\theta^{e}, a ; D\right)$ is the steady-state measure of plants with age $a$ and the expected idiosyncratic productivity $\theta^{e}$. More specifically,

$$
\begin{aligned}
& f^{s s}\left(\theta_{u}, a ; D\right)=f^{s s}(0, D)(1-p)^{a} \\
& f^{s s}\left(\theta_{g}, a ; D\right)=f^{s s}(0, D) \varphi\left[1-(1-p)^{a}\right]
\end{aligned}
$$

By definition, a steady state features time-invariant distribution of plants across $a$ and $\theta^{e}$. This implies that $P A$ has to be time-invariant for (8) to hold.

In addition to demand condition as $(8), f^{s s}(0, D), \bar{a}_{u}^{s s}(D)$ and $\bar{a}_{g}^{s s}(D)$ have to satisfy the following conditions. The exit condition for a good plant is:

$$
\left(\alpha^{\frac{\alpha}{1-\alpha}}-\alpha^{\frac{1}{1-\alpha}}\right)\left[\frac{P A \theta_{g}}{(1+\gamma)^{\bar{a}_{g}^{s s}(D)}}\right]^{\frac{1}{1-\alpha}}-\Psi=0
$$

The exit condition for an unsure plant is

$$
\begin{aligned}
0= & \left(\alpha^{\frac{\alpha}{1-\alpha}}-\alpha^{\frac{1}{1-\alpha}}\right)\left[\frac{P A \theta_{u}}{(1+\gamma)^{\bar{a}_{u}^{s s}(D)}}\right]^{\frac{1}{1-\alpha}}-\Psi+ \\
& p \varphi \sum_{a=\bar{a}_{u}^{s s}(D)+1}^{\bar{a}_{g}^{s s}(D)} \beta^{a-\bar{a}_{u}^{s s}(D)}\left\{\left(\alpha^{\frac{\alpha}{1-\alpha}}-\alpha^{\frac{1}{1-\alpha}}\right)\left[\frac{P A \theta_{g}}{(1+\gamma)^{a}}\right]^{\frac{1}{1-\alpha}}-\Psi\right\} ;
\end{aligned}
$$

The free entry condition is:

$$
\begin{aligned}
c_{0}+c_{1} f^{s s}(0, D)= & \sum_{a=0}^{\bar{a}_{u}^{s s}(D)} \beta^{a}(1-p)^{a}\left\{\left(\alpha^{\frac{\alpha}{1-\alpha}}-\alpha^{\frac{1}{1-\alpha}}\right)\left[\frac{P A \theta_{u}}{(1+\gamma)^{a}}\right]^{\frac{1}{1-\alpha}}-\Psi\right\}+ \\
& \sum_{a=0}^{\bar{a}_{g}^{s s}(D)} \beta^{a} \varphi\left[1-(1-p)^{a}\right]\left\{\left(\alpha^{\frac{\alpha}{1-\alpha}}-\alpha^{\frac{1}{1-\alpha}}\right)\left[\frac{P A \theta_{g}}{(1+\gamma)^{a}}\right]^{\frac{1}{1-\alpha}}-\Psi\right\} .
\end{aligned}
$$

Furthermore, (10) suggests:

$$
(P A)^{\frac{1}{1-\alpha}}=\frac{\Psi}{\left(\alpha^{\frac{\alpha}{1-\alpha}}-\alpha^{\frac{1}{1-\alpha}}\right)}\left[\frac{(1+\gamma)^{\bar{a}_{g}^{s s}(D)}}{\theta_{g}}\right]^{\frac{1}{1-\alpha}}
$$


Plugging (13) and (9) into (8) gives

$$
D=\frac{\Psi}{\left(\alpha^{\frac{\alpha}{1-\alpha}}-\alpha^{\frac{1}{1-\alpha}}\right)}\left[\frac{(1+\gamma)^{\bar{a}_{g}^{s s}(D)}}{\theta_{g}}\right]^{\frac{1}{1-\alpha}} f^{s s}(0, D)\left\{\begin{array}{c}
\sum_{a=0}^{\bar{a}_{u}^{s s}(D)}(1-p)^{a} \alpha^{\frac{\alpha}{1-\alpha}}\left[\frac{\theta_{u}}{(1+\gamma)^{a}}\right]^{\frac{1}{1-\alpha}}+ \\
\sum_{g=0}^{s s}(D) \\
\sum_{a=0}\left[1-(1-p)^{a}\right] \alpha^{\frac{\alpha}{1-\alpha}}\left[\frac{\theta_{g}}{(1+\gamma)^{a}}\right]^{\frac{1}{1-\alpha}}
\end{array}\right\}
$$

Plugging (13) into (11) gives

$$
\begin{aligned}
& \frac{1-\beta^{\bar{a}_{g}^{s s}(D)-\bar{a}_{u}^{s s}(D)+1}}{1-\beta}=\left(\frac{\theta_{u}}{\theta_{g}}\right)^{\frac{1}{1-\alpha}}(1+\gamma)^{\frac{\bar{a}_{g}^{s s}(D)-\bar{a}_{u}^{s s}(D)}{1-\alpha}}+ \\
& p \varphi \frac{\frac{\beta}{(1+\gamma)^{\frac{1}{1-\alpha}}}}{1-\frac{\beta}{(1+\gamma)^{\frac{1}{1-\alpha}}}}\left[(1+\gamma)^{\frac{\bar{a}_{g}^{s s}(D)-\bar{a}_{u}^{s s}(D)}{1-\alpha}}-\beta^{\bar{a}_{g}^{s s}(D)-\bar{a}_{u}^{s s}(D)}\right]
\end{aligned}
$$

Notice that $D$ does not enter (15), so that, as long as (15) determines an unique value for $\bar{a}_{g}^{s s}(D)-$ $\bar{a}_{u}^{s s}(D),(14)$ and (12) (with (13) plugged in) would jointly determine $\bar{a}_{g}^{s s}(D)$ and $f^{s s}(0, D)$ with $\bar{a}_{u}^{s s}(D)=\bar{a}_{g}^{s s}(D)-\left(\bar{a}_{g}^{s s}(D)-\bar{a}_{u}^{s s}(D)\right)$. It turns out that, for (15) to reveal a unique solution for $\bar{a}_{g}^{s s}(D)-\bar{a}_{u}^{s s}(D)$, it requires that $\theta_{u}<\theta_{g}$, which holds by definition. This proves Proposition 1.

Proof. Proposition 2. Plugging (13) into (12) gives

$$
\begin{aligned}
c_{0}+c_{1} f^{s s}(0, D)= & \sum_{a=0}^{\bar{a}_{u}^{s s}(D)} \beta^{a}(1-p)^{a} \Psi\left\{\left[\frac{(1+\gamma)^{\bar{a}_{g}^{s s}(D)}}{\theta_{g}}\right]^{\frac{1}{1-\alpha}}\left[\frac{\theta_{u}}{(1+\gamma)^{a}}\right]^{\frac{1}{1-\alpha}}-1\right\}+ \\
& \sum_{a=0}^{\bar{a}_{g}^{s s}(D)} \beta^{a} \varphi\left[1-(1-p)^{a}\right] \Psi\left\{\left[\frac{(1+\gamma)^{\bar{a}_{g}^{s s}(D)}}{\theta_{g}}\right]^{\frac{1}{1-\alpha}}\left[\frac{\theta_{g}}{(1+\gamma)^{a}}\right]^{\frac{1}{1-\alpha}}-1\right\},
\end{aligned}
$$

which suggests

$$
f^{s s}(0, D)=\left(\begin{array}{c}
\sum_{a=0}^{\bar{a}_{u}^{s s}(D)} \beta^{a}(1-p)^{a} \Psi\left\{\left[\frac{(1+\gamma)^{\bar{a}_{g}^{s s}(D)}}{\theta_{g}}\right]^{\frac{1}{1-\alpha}}\left[\frac{\theta_{u}}{(1+\gamma)^{a}}\right]^{\frac{1}{1-\alpha}}-1\right\}+ \\
\sum_{a=0}^{s s} \beta^{a} \varphi\left[1-(1-p)^{a}\right] \Psi\left\{\left[\frac{(1+\gamma)^{\bar{a}_{g}^{s s}(D)}}{\theta_{g}}\right]^{\frac{1}{1-\alpha}}\left[\frac{\theta_{g}}{(1+\gamma)^{a}}\right]^{\frac{1}{1-\alpha}}-1\right\}-c_{0}
\end{array}\right) / c_{1} .
$$


Combining (14) and (17) gives

$$
\begin{aligned}
& D=\frac{\Psi}{\left(\alpha^{\frac{\alpha}{1-\alpha}}-\alpha^{\frac{1}{1-\alpha}}\right)}\left[\frac{(1+\gamma)^{\bar{a}_{g}^{s s}(D)}}{\theta_{g}}\right]^{\frac{1}{1-\alpha}}\left\{\begin{array}{c}
\sum_{a=0}^{\bar{a}_{u}^{s s}(D)}(1-p)^{a} \alpha^{\frac{\alpha}{1-\alpha}}\left[\frac{\theta_{u}}{(1+\gamma)^{a}}\right]^{\frac{1}{1-\alpha}}+ \\
\bar{a}_{g}^{s s}(D) \\
\sum_{a=0} \varphi\left[1-(1-p)^{a}\right] \alpha^{\frac{\alpha}{1-\alpha}}\left[\frac{\theta_{g}}{(1+\gamma)^{a}}\right]^{\frac{1}{1-\alpha}}
\end{array}\right\} . \\
& \left(\begin{array}{c}
\sum_{a=0}^{\bar{a}_{u}^{s s}(D)} \beta^{a}(1-p)^{a} \Psi\left\{\left[\frac{(1+\gamma)^{\bar{a}_{g}^{s s}(D)}}{\theta_{g}}\right]^{\frac{1}{1-\alpha}}\left[\frac{\theta_{u}}{(1+\gamma)^{a}}\right]^{\frac{1}{1-\alpha}}-1\right\}+ \\
\sum_{a=0}^{\bar{a}_{g}^{s s}(D)} \beta^{a} \varphi\left[1-(1-p)^{a}\right] \Psi\left\{\left[\frac{(1+\gamma)^{\bar{a}_{g}^{s s}(D)}}{\theta_{g}}\right]^{\frac{1}{1-\alpha}}\left[\frac{\theta_{g}}{(1+\gamma)^{a}}\right]^{\frac{1}{1-\alpha}}-1\right\}-c_{0}
\end{array}\right) / c_{1} .
\end{aligned}
$$

where $\bar{a}_{u}^{s s}(D)=\bar{a}_{g}^{s s}(D)-\left(\bar{a}_{g}^{s s}(D)-\bar{a}_{u}^{s s}(D)\right)$ with $\left(\bar{a}_{g}^{s s}(D)-\bar{a}_{u}^{s s}(D)\right)$ determined by (15) independently. Apparently, the right-hand side of (18) increases monotonically in $\bar{a}_{g}^{s s}(D)$. This implies that higher $D$ leads to higher $\bar{a}_{g}^{s s}(D)$ and $\bar{a}_{u}^{s s}(D)$. Moreover, the right-hand side of (17) also increases monotonically in $\bar{a}_{g}^{s s}(D)$, which suggests that, by causing higher $\bar{a}_{g}^{s s}(D)$, higher $D$ will also give higher $f^{s s}(0, D)$. This proves Proposition 3 .

\subsection{Approximating Value Functions with Krusell \& Smith (1998) Approach}

The key computational task is to map $F$, the plant distribution across ages and idiosyncratic productivity, given demand level $D$, into a set of value functions $V\left(\theta^{e}, a ; F, D\right)$. To make the state space tractable, we define a variable $X$ such that:

$$
X(F)=\sum_{a} \sum_{\theta^{e}} f\left(\theta^{e}, a\right) \cdot q\left(\theta^{e}, a\right)
$$

where $f\left(\theta^{e}, a\right)$, as a component of $F$, measures the mass of plants with expected idiosyncratic productivity $\theta^{e}$ and age $a$. Apparently,

$$
P(F, D) \cdot A=\frac{D}{X\left(F^{\prime}\right)}=\frac{D}{X(H(F, D))} .
$$

$F^{\prime}$ is the updated plant distribution after entry and exit and $F^{\prime}=H(F, D) ; P(F, D)$ is the equilibrium price in a period with initial aggregate state $(F, D)$. Plugging $(20)$ into $(3)$ gives

$$
\pi(a, \theta ; F, D)=\left(\alpha^{\frac{\alpha}{1-\alpha}}-\alpha^{\frac{1}{1-\alpha}}\right)\left[\frac{D}{X(H(F, D))}\right]^{\frac{1}{1-\alpha}}\left[\frac{\theta^{e}}{(1+\gamma)^{a}}\right]^{\frac{1}{1-\alpha}}-\Psi .
$$

Thus, the aggregate state $(F, D)$ and its law of motion help plants to predict future profitability by suggesting sequences of $X$ 's from today onward under different paths of demand realizations. The question then is: what is the plant's critical level of knowledge of $F$ that allows it to predict the sequence of $X^{\prime} s$ over time? Although plants would ideally have full information about $F$, this is not computationally feasible. Therefore we need to find an information set $\Omega$ that delivers a good 


\begin{tabular}{|c|c|}
\hline$\Omega$ & $\{X\}$ \\
\hline$H_{\Omega}$ & $\begin{array}{l}H_{x}\left(X, D_{h}\right): \log X^{\prime}=0.0415+0.9937 \log X \\
H_{x}\left(X, D_{l}\right): \log X^{\prime}=0.0495+0.9924 \log X\end{array}$ \\
\hline$R^{2}$ & $\begin{array}{l}\text { for } D_{h}: 0.9996 \\
\text { for } D_{l}: 0.9989\end{array}$ \\
\hline standard forecast error & $\begin{array}{l}\text { for } D_{h}: 4.4 \cdot 10^{-7 \%} \\
\text { for } D_{l}: 4.7 \cdot 10^{-7 \%}\end{array}$ \\
\hline maximum forecast error & $\begin{array}{l}\text { for } D_{h}: 1.76 \cdot 10^{-6 \%} \\
\text { for } D_{l}: 1.78 \cdot 10^{-6 \%}\end{array}$ \\
\hline $\begin{array}{l}\text { Den Haan \& Marcet test sta- } \\
\text { tistic }\left(\chi_{7}^{2}\right)\end{array}$ & 0.4228 \\
\hline
\end{tabular}

Table 7: The Estimated Laws of Motion and Measures of Fit

approximation of plants' equilibrium behavior, yet is small enough to reduce the computational difficulty.

We look for an $\Omega$ through the following procedure. In step 1 , we choose a candidate $\Omega$. In step 2 , we postulate perceived laws of motion for all members of $\Omega$, denoted $H_{\Omega}$, such that $\Omega^{\prime}=H_{\Omega}(\Omega, D)$. In step 3, given $H_{\Omega}$, we calculate plants' value functions on a grid of points in the state space of $\Omega$ applying value function iteration, and obtain the corresponding industry-level decision rules - entry sizes and exit ages across aggregate states. In step 4, given such decision rules and an initial plant distribution. We simulate the behavior of a continuum of plants along a random path of demand realizations, and derive the implied aggregate behavior - a time series of $\Omega$. In step 5, we use the stationary region of the simulated series to estimate the implied laws of motion and compare them with the perceived $H_{\Omega}$; if different, we update $H_{\Omega}$, return to step 3 and continue until convergence. In step 6 , once $H_{\Omega}$ converges, we evaluate the fit of $H_{\Omega}$ in terms of tracking the aggregate behavior. If the fit is satisfactory, we stop; if not, we return to step 1, make plants more knowledgeable by expanding $\Omega$, and repeat the procedure.

We start with $\Omega=\{X\}$ - plants observe $X$ instead of $F$. We further assume that plants perceive the sequence of future coming $X^{\prime} s$ as depending on nothing more than the current observed $X$ and the state of demand. The perceived law of motion for $X$ is denoted $H_{x}$ so that $X^{\prime}=$ $H_{x}(X, D)$. We then apply the procedure described above and simulate the behavior of a continuum of plants over 10000 periods. The results are presented in Table 5 .

As shown in Table 5, the estimated $H_{x}$ is log-linear. The fit of $H_{x}$ is quite good, as suggested by the high $R^{2}$, the low standard forecast error, and the low maximum forecast error. The good fit when $\Omega=\{X\}$ implies that plants perceiving these simple laws of motion make only small mistakes in forecasting future prices. To explore the extent to which the forecast error can be explained by variables other than $X$, we implement the Den Haan and Marcet (1994) test using instruments $\left[1, X, \mu_{a}, \sigma_{a}, \gamma_{a}, \kappa_{a}, r_{u}\right]$, where $\mu_{a}, \sigma_{a}, \gamma_{a}, \kappa_{a}, r_{u}$ are the mean, standard deviation, skewness, and kurtosis of the age distribution of plants, and the fraction of unsure plants, respectively. The test statistic is 0.4228 , well below the critical value at the $1 \%$ level. This suggests that given the estimated laws of motion, we do not find much additional forecasting power contained in other 


\begin{tabular}{|c|c|}
\hline$\Omega$ & $\left\{X, \sigma_{a}\right\}$ \\
\hline$H_{\Omega}$ & $\begin{array}{l}\text { booms }(\log X): \\
\log X^{\prime}=-1.0406+0.9954 \log X+0.1262 \sigma_{a} \\
\text { booms }\left(\sigma_{a}\right): \\
\sigma_{a}^{\prime}=0.2785-0.0068 \log X+0.9754 \sigma_{a} \\
\text { recessions }(\log X): \\
\log X^{\prime}=-1.0371+0.9963 \log X+0.8988 \sigma_{a} \\
\text { recessions }\left(\sigma_{a}\right): \\
\quad \sigma_{a}^{\prime}=0.2775-0.0065 \log X+0.9751 \sigma_{a}\end{array}$ \\
\hline$R^{2}$ & $\begin{array}{l}\text { booms }(\log X): 0.9999 \\
\text { recessions }(\log X): 0.99999 \\
\text { booms }\left(\sigma_{a}\right): 0.9989 \\
\text { recessions }\left(\sigma_{a}\right): 0.9990\end{array}$ \\
\hline $\begin{array}{l}\text { standard forecast } \\
\text { error }\end{array}$ & $\begin{array}{l}\text { booms }(\log X): 1.1 \cdot 10^{-8 \%} \\
\text { recessions }(\log X): 1.2 \cdot 10^{-8 \%} \\
\text { booms }\left(\sigma_{a}\right): 6.4 \cdot 10^{-9} \% \\
\text { recessions }\left(\sigma_{a}\right): 6.25 \cdot 10^{-9} \%\end{array}$ \\
\hline $\begin{array}{l}\text { maximum forecast } \\
\text { error }\end{array}$ & $\begin{array}{l}\text { booms }(\log X): 4.87 \cdot 10^{-8 \%} \\
\text { recessions }(\log X): 5.05 \cdot 10^{-8 \%} \\
\text { booms }\left(\sigma_{a}\right): 1.48 \cdot 10^{-8 \%} \\
\text { recessions }\left(\sigma_{a}\right): 1.51 \cdot 10^{-8 \%}\end{array}$ \\
\hline $\begin{array}{l}\text { Den Haan \& } \\
\text { Marcet test statis- } \\
\text { tic }\left(\chi_{7}^{2}\right)\end{array}$ & 0.4375 \\
\hline
\end{tabular}

Table 8: The Estimated Laws of Motion with two moments and Measures of Fit

variables. Nevertheless, we expand $\Omega$ further to include $\sigma_{a}$, the standard deviation of the age distribution of firms. The results when $\Omega=\left\{X, \sigma_{a}\right\}$ are shown in Table 6 . 


\section{REFERENCES}

Aruoba, S. Boragan; Rubio-Ramirez, Juan F. and Fernandez-Villaverde, Jesus. "Comparing Solution Methods for Dynamic Equilibrium Economies." Working Paper 2003-27, Federal Reserve Bank of Atlanta, 2003.

Aw, Bee Yan; Chen, Xiaomin and Roberts, Mark J. "Firm-level Evidence on Productivity Differentials, Turnover, and Exports in Taiwanese Manufacturing." Journal of Development Economics, October 2001, 66(1), pp. 51-86.

Baily, Martin Neil; Bartelsman, Eric J. and Haltiwanger, John. "Labor Productivity: Structural Change and Cyclical Dynamics." Review of Economics and Statistics, August 2001, 83(3), pp. $420-433$.

Baldwin, John R. The Dynamics of Industrial Competition. Cambridge University Press, 1995.

Barlevy, Gadi. "The Sullying Effect of Recessions." Review of Economic Studies, January 2002, 69(1), p65-96.

Basu, Sustanto. "Procyclical Productivity: Increasing Returns or Cyclical Utilization?" Quarterly Journal of Economics, August 1996, 111(3), pp. 719-51.

Basu, Susanto; Fernald, John G. and Shapiro, Matthew D. "Productivity Growth in the 1990s: Technology, Utilization, or Adjustment?" NBER Working paper 8359, 2001.

Campbell, Jeffrey R. and Fisher, Jonas D.M. "Technology Choice and Employment Dynamics at Young and Old Plants." Working Paper Series-98-24, Federal Reserve Bank of Chicago, 1998.

Campbell, Jeffery R. and Fisher, Jonas D.M. "Aggregate Employment Fluctuations with Microeconomic Asymmetries" American Economic Review 90 (5), 1323 - 1345.

Campbell, Jeffrey R. and Fisher, Jonas D.M. "Idiosyncratic Risk and Aggregate Employment Dynamics." Review of Economic Dynamics, 2004, pp.331-353.

Davis, Steven J. and Haltiwanger, John. "Gross Job Flows." Handbook of Labor Economics, Amsterdam: North-Holland, 1999.

Davis, Steven J.; Haltiwanger, John and Schuh, Scott. Job Creation and Job Destruction, Cambridge, MIT Press,1996.

Davis, Steven J. and Haltiwanger, John. "Gross Job Creation, Gross Job Destruction, and Employment Reallocation." Quarterly Journal of Economics, August 1992, 107(3), pp. 818-63.

Den Haan, Wouter J. and Marcet, Albert. "Accuracy in Simulations." Review of Economic Studies, 1994, 61, pp. 3-18. 
Dunne, Timothy; Roberts, Mark J. and Samuelson, Larry. "The Growth and Failure of U.S. Manufacturing Plants." Quarterly Journal of Economics, November 1989, 104(4), pp. 67198.

Gomes, Joao, Jeremy Greenwood, and Sergio Rebelo. "Equilibrium Unemployment." Journal of Monetary Economics, August 2001, 48(1), pp. 109-52.

Goolsbee, Austan. "Investment Tax Incentives, Prices, and the Supply of Capital Goods." Quarterly Journal of Economics, February 1998, 113(1), pp. 121-148.

Lucas, Robert, E. "On the Size Distribution of Business Firms." The Bell Journal of Economics, Autumn1978, 9(2), pp. 508-523.

Jensen, J. Bradford; McGuckin, Robert H. and Stiroh, Kevin J. "The Impact of Vintage and Survival on Productivity: Evidence from Cohorts of U.S. Manufacturing Plants." Economic Studies Series Working paper 00-06, Census of Bureau, May 2000.

Jovanovic, Boyan. "Selection and the Evolution of Industry." Econometrica, May 1982, 50(3), pp. $649-70$.

Krusell, Per. and Smith, Anthony A. Jr. "Income and Wealth Heterogeneity in the Macroeconomy." Journal of Political Economy, 1998, 106(5), pp. 867-895.

Ouyang, Min. "The Scarring Effect of Recessions", University of California at Irvine, Working paper series, 2005.

Pries, Michael J. "Persistence of Employment Fluctuations: a Model of Recurring Firm Loss." Review of Economic Studies, January 2004, 71(1), pp. 193-215.

Young, Eric R. "Approximate Aggregation: an Obstacle Course for the Krusell-Smith Algorithm." Florida University, 2002. 